\title{
Políticos, eleições e receitas públicas
}

\section{Resumo}

Este artigo analisa o impacto das características pessoais dos prefeitos brasileiros no oportunismo. Em anos eleitorais, de maneira geral, os prefeitos manipulam as receitas públicas. Quando é investigado o impacto das características dos prefeitos nos ciclos políticoorçamentários, os resultados indicam que a idade, a ideologia, a formação superior, o alinhamento com o presidente da República e com o governador de estado têm um impacto condicional no oportunismo, contudo o gênero, não tem influência sobre o nível das manipulações pré-eleitorais.

Palavras-Chave: Ciclos político-orçamentários; Finanças públicas; Governos locais; Eleições; Brasil

JEL: D7, H7, P16

\begin{abstract}
This article analyses the impact of the personal characteristics of the Mayors on the opportunism at the local government in Brazil. Brazilian's Mayors, in general, manipulate the revenues in elections years. When we investigate the impact of the characteristics of the Mayor in the political budget cycles at local government, the results indicate that age, ideology, high education, alignment with the President, and with the Governor, have a conditional effect on opportunism. In the other hand, gender does not have impact on the level of the pre-election manipulation.
\end{abstract}

Keywords: Political budget cycles; Public finance; Local governments; Elections; Brazil 


\section{INTRODUÇÃO}

Um comportamento muitas vezes observado nas nações democráticas é o de elevações nas despesas nos períodos que antecedem às eleições. Ao utilizarem essa artimanha os incumbentes esperam, segundo Rogoff e Sibert (1988), aumentar a suas chances de reeleição. A literatura sobre as manipulações pré-eleitorais com objetivos oportunistas existente para o Brasil é focada nessas alterações nas despesas públicas ${ }^{1}$, relevando às receitas uma análise mais superficial ${ }^{2}$. É sabido que o grau de discricionariedade das despesas públicas é muito mais elevado que o relativo às receitas públicas, dada a existência de uma maior rigidez na criação/extinção de tributos, no entanto, os prefeitos brasileiros podem alterar as alíquotas dos impostos e conceder isenções e benefícios fiscais.

Segundo a Pesquisa de Informações Básicas Municipais (PIBM) $2015^{3}$ do IBGE (Instituto Brasileiro de Geografia e Estatística) em 2014, 3.437 dos 5570 municípios brasileiros concediam algum tipo de benefício fiscal à implementação de empreendimentos. Ainda de acordo com a PIBM, em 2014, 1358 municípios isentaram empreendimentos do pagamento de Impostos Predial e Territorial Urbana (IPTU), 996 reduziram a cobrança do IPTU, outros 996 governos municipais brasileiros concederam isenções relacionadas ao Imposto Sobre Serviços de Qualquer Natureza (ISS) e 1210 não cobraram taxas e tarifas. Pelo outro lado, 245 governos locais possuem tributos como mecanismo de impedimento de instalação de empreendimento. Esse panorama demonstra que os prefeitos brasileiros possuem margem de manobra também nas receitas e esse poder discricionário deixa margem à manipulações nas receitas em anos eleitorais.

As operações de crédito também são discricionárias e por terem sido trazidas ao debate público no Brasil no final de 2015 e em 2016 em decorrência da abertura do processo de impeachment da Presidente da República, merecem ser analisadas. No mesmo sentido, os recursos advindos de alienações de património público também são discricionários e por conta disso, podem sofrer impacto do oportunismo e devem ser investigados. Ao se extrapolar a análise dos níveis agregados de receitas públicas (próprias, corrente, de capital, tributárias) para as componentes da receita tributária, às receitas advindas de operações de crédito e às alienações do património público, é possível elaborar um estudo aprofundado sobre o impacto do oportunismo nas receitas públicas municipais e assim será preenchida essa lacuna existente

\footnotetext{
${ }^{1}$ Meneguin et al. (2005), Nakaguma e Bender (2010), Sakurai e Menezes-Filho (2011).

${ }^{2}$ Sakurai e Menezes-Filho (2011) constataram que as receitas próprias são reduzidas em anos eleitorais nos municípios brasileiros e Nakaguma e Bender (2010) evidenciaram um comportamento oposto nos estados brasileiros, com aumentos na receita total, corrente, tributaria, de capital e nas transferências correntes recebidas pelos estados.

${ }^{3}$ Disponível em: http://www.ibge.gov.br/home/estatistica/economia/perfilmunic/2015/default_xls.shtm
} 
na literatura sobre o oportunismo no Brasil. Para tal, nesse artigo foram analisados 2228 dos 5570 municípios brasileiros durante os anos de 2001 e 2012 e evidenciou-se um comportamento oportunista na condução das receitas públicas em anos eleitorais, com nomeadamente com reduções nos tributos diretos (ITBI ${ }^{4}$, IPTU e as taxas e tarifas). Constatou-se, também que as características do prefeito (idade, ideologia, formação superior, alinhamento com o presidente da República e com o governador de estado) influenciam na magnitude das manipulações pré-eleitorais.

\section{REFERENCIAL TEÓRICO.}

Segundo Rogoff e Sibert (1988) o comportamento oportunista típico nas receitas tributárias é o de reduções das mesmas em anos eleitorais, pois isso sinaliza aos eleitores uma maior competência do governante, desta forma, reduções nos tributos antes das eleições, aumentariam as chances de reeleição do incumbente. No entanto, ao reduzir os impostos antes das eleições, os governantes podem gerar uma piora do resultado orçamentário, que só será percebido pelos cidadãos e corrigido no ano subsequente às votações. Essa prática recebeu a denominação de ciclos político-orçamentários, pelo fato de gerar uma redução nas receitas tributárias antes das eleições e um aumento nas mesmas no ano seguinte. Esse fenômeno pode ser prejudicial à economia, pois pode gerar ineficiências decorrentes da mudança nos impostos, uma vez que as expectativas dos agentes poderão ser frustradas por essas manipulações pré-eleitorais.

Na seara empírica, Mikessell (1978) evidenciou a existência de ciclos eleitorais nos impostos dos estados norte-americanos, sendo que os governantes manipulam as receitas tributárias levando em consideração as preferências dos eleitores (elasticidades). Já Yoo (1998) analisou o comportamento oportunista dos governantes japoneses na condução das receitas tributarias e constatou que no ano antecedente às eleições para o parlamento, há reduções dos impostos discricionários, especialmente pelo fato da data das eleições serem endógenas, ou seja, é o governo quem define a data das votações. O trabalho de Volkerink e De Haan (1999) investigou o impacto da ideologia sobre os impostos nas nações da OCDE e evidenciou que os políticos de direita tendem a aumentar os impostos sobre rendimento dos contribuintes e contribuições sociais, contudo, o impacto da ideologia do governantes sobre os impostos é dinâmica e muda ao longo do tempo.

\footnotetext{
${ }^{4}$ Imposto Sobre Transmissão de Imóveis (ITBI)
} 
No que concerne aos países em desenvolvimento Ehrhart (2012) evidenciou um perfil oportunista na condução das receitas públicas, nomeadamente, reduções nos impostos em anos eleitorais. Katsimi e Sarantides (2012), por sua vez, evidenciaram que nos países da OCDE há, em anos eleitorais, uma redução nos impostos diretos, que são percebidos mais facilmente pelos eleitores. Por outro lado o trabalho de Andrikopoulos et al. (2006) e de Karakaş (2013) não constataram oportunismo na condução das receitas públicas nos países da União Europeia e das prefeituras turcas, respectivamente. Na mesma direção, Ashworth e Heyndels (2002) evidenciaram que nos países da OCDE, os governantes não alteram a estrutura dos impostos nos períodos eleitorais, pois consideram que os eleitores preferem que haja manutenção da composição das receitas tributarias.

Os resultados de Binet e Pentecôte (2004) indicam que os governantes dos municípios franceses, diminuem a arrecadação de impostos no ano eleitoral e no antecedente, da mesma forma Foremmy e Riedel (2014) chegaram à conclusões similares para o poder local alemão, contudo, essa redução nas receitas tributárias é acompanhada de elevações nas mesmas nos anos posteriores às eleições, o que caracteriza um ciclo eleitoral nas receitas tributárias. Os resultados obtidos para os municípios espanhóis por Vicente et al. (2013) indicam que o grau de transparência do governo local não tem impacto sobre a dinâmica dos impostos em anos eleitorais, enquanto, Alesina e Paradisi (2014) analisaram o oportunismo na escolha das alíquotas de um novo imposto municipal na Itália e constataram uma relação direta e proporcional entre o período até a realização da eleição e as alíquotas cobradas, sendo o CPO mais acentuado nas cidades menores, onde tal imposto possui um peso superior nas receitas municipais.

As receitas tributárias, contudo, não são constituídas exclusivamente por impostos e desta forma os governos geralmente possuem, sob sua competência, tarifas e taxas relativas à bens e serviços que os mesmo oferecem à população e que podem vir a ser manipuladas da mesma forma que os impostos. Nesse sentido, Klien (2014) analisou o comportamento das tarifas dos serviços oferecidos pelos governos locais austríacos e constatou que nos anos eleitorais os políticos são muito cautelosos e para evitarem serem punidos pelos eleitores, ou não aumentam essas taxas ou então elevam marginalmente.

\section{RECEITAS PÚBLICAS BRASILEIRAS}

A atual configuração do sistema tributário brasileiro foi definida em 1988 após a promulgação da nova Constituição. De acordo com Rezende (1995), Serra e Afonso (1999) e Mendes 
(2004) esse sistema possui como característica a alta concentração das receitas tributárias nas mãos do Governo Federal. O gráfico 1 demonstra essa realidade, em 2015 os municípios foram responsáveis por somente 7\% da receita tributaria total arrecadada no Brasil.

Gráfico 1: Receita tributária 2015

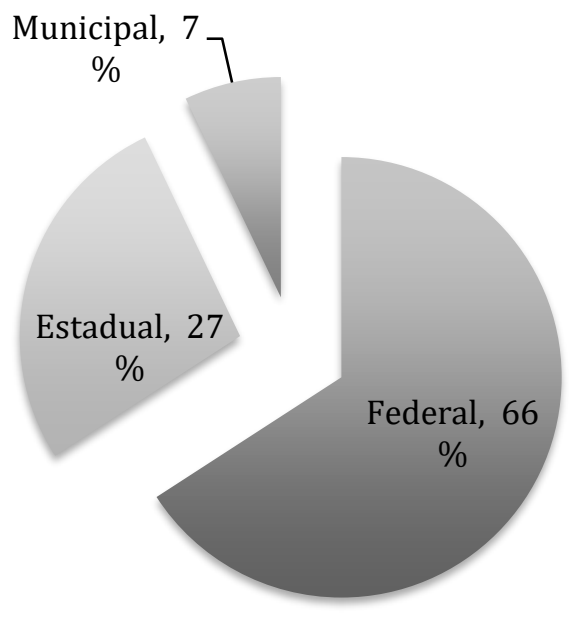

Fonte: Elaborado pelo autor com base na Nota Técnica Conjunta n ${ }^{a}$ 03/2016/CESEF/STN

Se formos utilizar o termo carga tributaria, ou seja, a participação das receitas tributarias em porcentagem do PIB (Produto Interno Bruto) temos que, segundo a nota técnica $n^{\circ} 03^{5}$ de 2016 da Secretaria do Tesouro Nacional (STN), os impostos cobrados pelas três esferas de governo do Brasil representaram, em 2015, 33\% do PIB. No gráfico 2 temos a participação de cada nível de governo na carga tributaria total.

Gráfico 2: Carga tributaria em \% do PIB em 2015

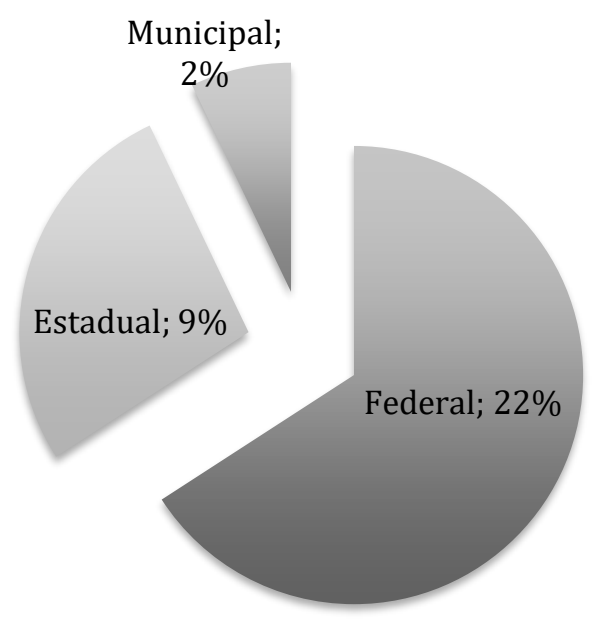

Fonte: Elaborado pelo autor com base na Nota Técnica Conjunta $n^{a}$ 03/2016/CESEF/STN

${ }^{5}$ Disponível em: http://www.cgu.gov.br/assuntos/auditoria-e-fiscalizacao/avaliacao-da-gestao-dos-administradores/prestacao-de-contas-dopresidente-da-republica/arquivos/2016/4-estimativa-da-carga-tributaria.pdf 
Uma das consequências dessa concentração financeira é, conforme indica o gráfico 3, a dependência dos municípios brasileiros dos recursos recebidos das outras duas esferas de governo (Federal e Estadual), que em 2013, as transferências representavam 60\% das receitas dos municípios brasileiros.

Gráfico 3: Componentes da receita pública municipal brasileira em 2013

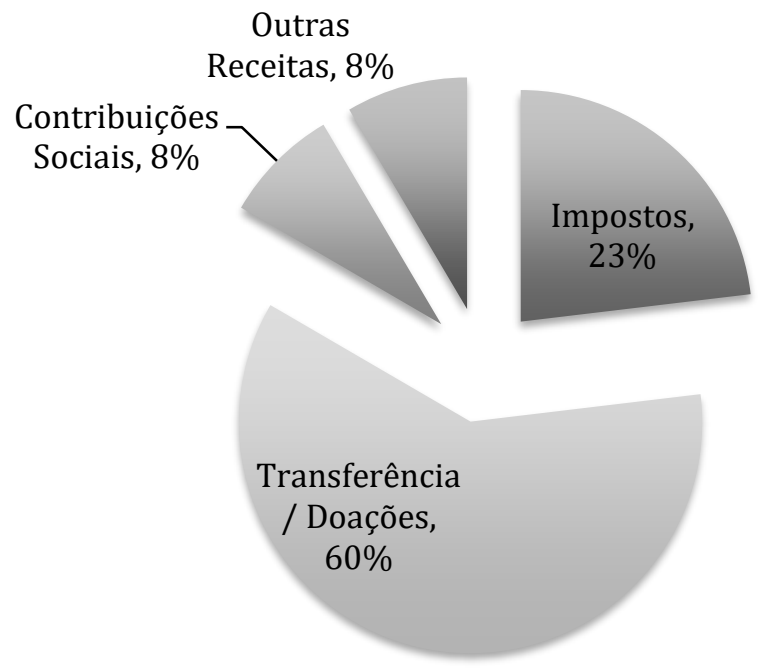

Fonte: Elaborado pelo autor com base na Nota Técnica Conjunta n ${ }^{a}$ 03/2016/CESEF/STN

No Brasil os municípios possuem competências sobre três impostos, o ITBI (Imposto sobre a transmissão de imóveis), o IPTU (Imposto Predial e Territorial Urbano) e o ISS (Imposto Sobre Serviços de Qualquer Natureza), sendo os dois primeiros diretos e o outro indireto.

Gráfico 4: Componentes da receita tributária dos municípios brasileiros em 2015

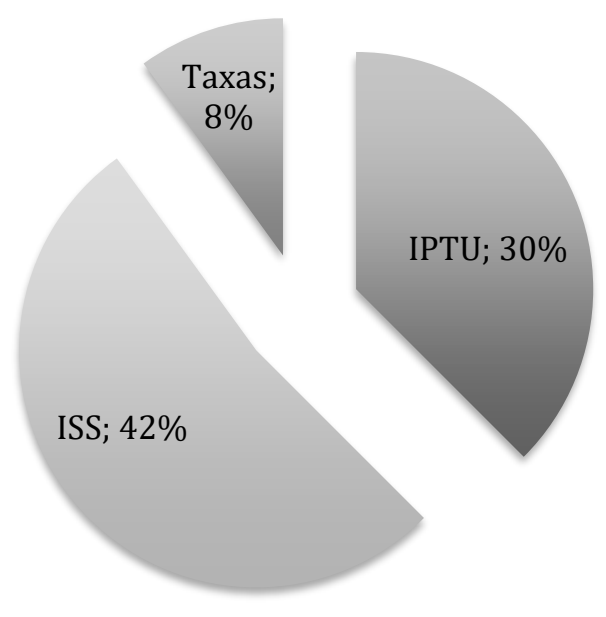

Fonte: Elaborado pelo autor com base na Nota Técnica Conjunta na 03/2016/CESEF/STN 
No gráfico 4 estão expostas a evolução da participação do IPTU, do ISS e das taxas e tarifas no total da receita tributária ${ }^{6}$ em 2015.

\section{DADOS E MODELO}

\subsection{Descrição das variáveis e fontes dos dados}

Para representar as receitas públicas dos municípios brasileiros e assim ser possível investigar o comportamento das mesmas foram propostas as variáveis: Rprop $_{i, t}$ e Tributos $_{i, t}$ que representam, respectivamente, as receitas próprias e os recursos advindos de tributos do município $i$ no ano $t$. Para financiar as suas despesas, os municípios possuem três impostos sob sua competência o IPTU, o ITBI e o ISS. Para ser possível investigar como os três impostos se comportam em anos eleitorais temos: $I P T U_{i, t}$ representa as receitas com o IPTU, $I_{T B} I_{i, t}$ as receitas com o ITBI e $I S S_{i, t}$ as oriundas do ISS. No Brasil dos 5570 municípios, 5218 possuem pelo menos um taxa ou tarifas, então para representá-las há a variável Taxas $_{i, t}$ que são os recursos arrecadados com taxas e tarifas públicas ${ }^{7}$ do município $i$ no exercício orçamentário $t$.

Como esse artigo pretende analisar se existe oportunismo pré-eleitoral nas receitas dos municípios brasileiros é importante ir além das receitas tributárias e avaliar o comportamento dos recursos advindos de operações de crédito e de alienações de patrimônio público representados, respectivamente, pelas variáveis OCredito $_{i, t}$ e Alienação $_{i, t}$. A Lei de Responsabilidade Fiscal $^{8}$ (LRF) veio a gerar muitas regras sobre as operações de crédito $^{9}$, as mais importantes são que essa fonte de recursos deve sempre ser autorizada pelo poder legislativo e não pode exceder o montante de despesas de capital autorizado no orçamento (Lei Orçamentária Anual - LOA).

Sobre a alienação de patrimônio público, há dispositivos legais, nomeadamente o artigo $\mathrm{n}^{\circ} 44$ da LRF, que impede que esses recursos sejam usados para financiar despesas correntes. Os dados referentes às receitas públicas foram obtidos junto ao FINBRA (Finanças do Brasil Dados Contábeis dos Municípios) da Secretaria do Tesouro Nacional (STN) e foi aplicado logaritmo em todas as variáveis fiscais e as mesmas estão expressas em termos per-capita

\footnotetext{
${ }^{6}$ Não foi divulgado os valores referentes ao ITBI.

${ }^{7}$ Essas taxas e tarifas são: de Iluminação pública, coleta de lixo, incêndio, limpeza pública, poder de política e outros tipos de taxas e tarifas. ${ }^{8}$ Lei Complementar ${ }^{\circ} 101$, de 04 de maio de 2000.

${ }^{9}$ De acordo com o artigo 29 da LRF (Lei Complementar 101/2000) operação de crédito é todo o compromisso financeiro assumido em razão de mútuo, abertura de crédito, emissão e aceite de título, aquisição financiada de bens, recebimento antecipado da venda a termo de bens e serviços, arrendamento mercantil e outros derivativos financeiros, além da assunção, reconhecimento ou confissão de dívidas pelo Município.
} 
com preços constantes de 31 de dezembro de 2012. O IGP-DI, da Fundação Getúlio Vargas, foi o índice de preços utilizado para deflacionar os dados.

Esse artigo faz uso de um elevado número de variáveis de controle da realidade socioeconômica dos municípios brasileiros, dada a elevada desigualdade nos níveis de desenvolvimento, de renda e de riqueza existentes no Brasil. A variável $P I B_{i, t}$, que representa o produto interno bruto per-capita do município $i$ no ano $t$ e a variável $G N I_{i, t}$, que indica o coeficiente de Gini do governo local $i$ no ano $t$, são utilizadas para controlar para as diferentes realidades de níveis de riqueza e concentração de renda dos municípios brasileiros.

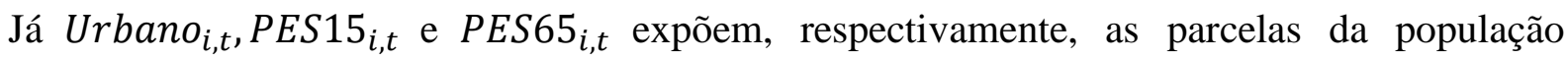
urbana, com menos de 15 anos e com mais de 65 do município $i$ no ano $t$. Ao fazer uso dessas variáveis, controla-se para as características demográficas das localidades brasileiras. Por fim, $T_{\_} A N A L F 15 M_{i, t}$ foi introduzida nas estimações pois a mesma funciona como uma proxy do inverso do estoque de capital humano, uma vez que representa a parcela da população com mais de 15 anos do município $i$ que era analfabeta no ano $t$. Os dados referentes ao PIB foram obtidos junto ao IBGE e as demais informações referentes à realidade socioeconômica são oriundas do Atlas Brasil ${ }^{10}$.

Como este trabalho pretende elaborar um estudo aprofundado no impacto do oportunismo nas receitas públicas municipais brasileiras, será investigado como as características dos Prefeitos influenciam ou não na condução das receitas públicas. Propõem-se para tal, as variáveis Feminino $_{i, t}$, Superior ${ }_{i, t}$, Idade $_{i, t}$, Esquerda ${ }_{i, t}$, Pres $_{i, t}$ e Gov,t. A variável binária Feminino $i, t$ assume 1 caso o governante do município $i$ no período $t$ seja do sexo feminino e zero caso contrário. Na mesma direção a variáveis dummy Superior ${ }_{i, t}$ assume o valor 1 caso o prefeito possua, pelo menos, o ensino superior completo e 0 caso não possua. Já a vaiável discreta $I_{d a d e} e_{i, t}$ representa a idade do Prefeito do município $i$ no ano $t$. Esquerda $a_{i, t}$ indica a ideologia do prefeito e assume 1 caso o mesmo seja de um partido de esquerda e zero caso seja de uma agremiação política de centro ou direita. Por fim, para representar o alinhamento político entre o prefeito e o presidente da República e o governador de estado há as variáveis Presi,t, e Govi,t que assumem, respectivamente, 1 caso o prefeito seja do mesmo partido do presidente e do governador e zero caso contrário. Na tabela 1 estão expostas as estatísticas descritivas das variáveis utilizadas no artigo.

Tabela 1: Estatísticas descritivas

(1)

(3)

(4)

${ }^{10}$ http://www.atlasbrasil.org.br/ 


\begin{tabular}{|c|c|c|c|c|c|}
\hline VARIABLES & $\mathrm{N}$ & mean & $\mathrm{sd}$ & $\min$ & $\max$ \\
\hline Rprop & 26,736 & 0.0967 & 0.168 & -0.321 & 2.473 \\
\hline Tributos & 26,736 & 4.296 & 0.949 & -0.909 & 9.004 \\
\hline Rcap & 25,319 & 3.629 & 1.561 & -13.40 & 8.946 \\
\hline OCredito & 26,736 & 8.942 & 31.03 & 0 & 1,007 \\
\hline Alienação & 26,736 & 4.598 & 13.77 & -0.000494 & 677.8 \\
\hline ITBI & 26,736 & 1.921 & 1.371 & -13.19 & 6.911 \\
\hline IPTU & 26,736 & 2.344 & 1.543 & -6.945 & 7.329 \\
\hline ISS & 26,736 & 2.986 & 1.312 & -6.420 & 8.225 \\
\hline Taxas & 26,736 & 1.985 & 1.330 & -7.870 & 6.751 \\
\hline Ano & 26,736 & 2,006 & 3.452 & 2,001 & 2,012 \\
\hline Eleição & 26,736 & 0.250 & 0.433 & 0 & 1 \\
\hline ApósEleição & 26,736 & 0.250 & 0.433 & 0 & 1 \\
\hline PES15 & 26,736 & 0.260 & 0.0473 & 0.00624 & 0.540 \\
\hline PES65 & 26,736 & 0.0816 & 0.0230 & 0.0136 & 0.247 \\
\hline Urbano & 26,736 & 0.682 & 0.219 & 0.0682 & 2.627 \\
\hline PIB & 26,736 & 2.274 & 0.700 & 0.147 & 6.239 \\
\hline T_ANALF15M & 26,736 & 13.06 & 8.479 & 0.750 & 50.34 \\
\hline GINI & 26,736 & 0.507 & 0.0630 & 0.279 & 0.800 \\
\hline Esquerda & 26,736 & 0.188 & 0.391 & 0 & 1 \\
\hline Feminino & 26,736 & 0.0636 & 0.244 & 0 & 1 \\
\hline Idade & 26,736 & 50.79 & 9.188 & 21 & 93 \\
\hline Superior & 26,736 & 0.474 & 0.499 & 0 & 1 \\
\hline Pres & 26,736 & 0.103 & 0.304 & 0 & 1 \\
\hline Gov & 26,736 & 0.221 & 0.415 & 0 & 1 \\
\hline
\end{tabular}

Fonte: Ministério da Fazenda do Brasil, Tribunal Superior Eleitoral, IBGE, Ipeadata, PNUD.

Nota: Todas as variáveis estão expressas em termos per capita a preços constantes de 31 de dezembro de 2012 . Foi aplicado logaritmo natural a todas as variáveis fiscais. separador de unidades.

O poder executivo municipal brasileiro é chefiado por prefeitos e pelos secretários municipais escolhidos pelo próprio prefeito. Os governantes locais brasileiros são eleitos diretamente por sufrágio universal, conjuntamente com o vice-prefeito, para mandatos de quatro anos. A legislação brasileira permite que o mandatário do poder local busque somente um segundo mandato consecutivo, desta forma, o prefeito só pode permanecer no poder por no máximo 8 anos consecutivos. O poder legislativo, por sua vez, é composto por vereadores eleitos por um sistema proporcional (Quociente Eleitoral) e que desempenham a função de criar leis e fiscalizar o poder executivo local.

Um ponto importante é que esses dois poderes são independentes entre si. $\mathrm{O}$ ato eleitoral para a escolha dos Prefeitos e dos Vereadores ocorre em simultâneo e é realizado sempre no primeiro domingo do mês de outubro. Nos municípios com mais de 200 mil eleitores, é necessário que o candidato mais votado ao cargo de chefe do executivos tenha $50 \%$ dos votos mais um, caso isso não ocorra, é necessário a realização de um segundo turno após no mínimo 10 dias do primeiro e também ocorre em um domingo do mês de outubro. Para representar os anos eleitorais temos a variável binária Eleiçã $o_{t}$ que assume 1 para os anos com sufrágios locais e zero caso contrário. Dado que se está a analisar a existência de ciclos políticoorçamentários, é necessário a utilização da variável ApósEleição $o_{t}$, que representa os anos que se seguem às eleições. Desta forma é possível constatar como as receitas se comportam nos anos com votações e no seguinte. 


\subsection{Modelo e método econométrico}

Para ser possível testar a existência de ciclos político-orçamentários nas receitas municipais brasileiras, propõem-se o seguinte modelo:

$$
y_{i, t}=\sum_{j=1}^{p} \theta_{j} y_{i, t-j}+D_{i, t}^{\prime} \beta_{1}+P_{i, t}^{\prime} \beta_{2}+O^{\prime}{ }_{t} \beta_{3}+\mu_{i}+\varepsilon_{i t} i=1, \ldots, 2228 ; t=1, \ldots, 11
$$

onde, $y_{i, t}$ representa a componente da receita que será analisa. $y_{i, t-j}$ é a variável dependente defasada, enquanto $D^{\prime}$ é um vetor composto pelas variáveis com as características demográficas de controlo e o vetor $P^{\prime}$ aglutina as variáveis que representam as caraterísticas dos prefeitos brasileiros. Já $O^{\prime}$ é o vetor que abrange as variáveis de oportunismo (Eleição $o_{t} \mathrm{e}$ ApósEleição $\left.o_{t}\right) . \mu_{i}$ representa os efeitos fixos e $\varepsilon_{i t}$ o termo de erro. $\theta_{j}, \beta_{1}, \beta_{2}$ e $\beta_{3}$ são os coeficientes a serem estimados.

O modelo econométrico será estimado segundo o método Sistema GMM (SGMM) desenvolvido por Arrelano e Bover (1995) e Blundell e Bond (1998). A escolha deste método é consequência das características dos dados e do modelo utilizados. A base de dados utilizada neste artigo é composta por informações de 2228 municípios espalhados pelos 26 estados brasileiros entre os anos de 2001 e 2012, isso significa que se está a trabalhar com dados em painel e, ao fazer isso, segundo Verbeek (2008), pode-se incorrer em problemas relacionados à heterocedasticidade e à autocorrelação do termo de erro. Os estimadores por efeitos fixos ou por efeitos aleatórios poderiam superar esses problemas, contudo, o modelo proposto acima é dinâmico, ou seja, a variável dependente defasada $\left(y_{i, t-j}\right)$ é utilizada como variável explicativa, e essa característica gera um problema de endogeineidade entre a variável dependente defasada e o termo de erro.

Segundo Roodman (2006), para superar esses problemas de heterocedasticidade, autocorrelação e endogeneidade, Arrelano e Bond (1991) elaboraram um método que primeiramente retira as diferenças aos estimadores e posteriormente aplica o Método dos Momentos Generalizados (GMM). Posteriormente Arrelano e Bover (1995) e Blundell e Bond (1998) desenvolveram o método SGMM que adiciona um pressuposto adicional ao estimador de Arrelano e Bond (1991), no qual as primeiras diferenças dos instrumentos não são correlacionadas com os efeitos fixos, ao fazer isso, aumenta-se a eficiência, dado o aumento do número de instrumentos, pois agora há um sistema de duas equações composto pela a original e a transformada. 
Quando se utilizam instrumentos é preciso assegurar que os mesmos sejam exógenos, ou seja, que não estejam correlacionados com o termo de erro e para isso utiliza-se o teste de Hansen ${ }^{11}$ que testa para a sobre-identificação dos instrumentos. Com a eficiência do estimador assegurada é preciso garantir a inferência estatística. Para tal, utiliza-se o procedimento proposto por Windmeijer (2005) que corrige os erros padrão gerados pelo método SGMM e permite que se realizem os testes de hipótese.

\section{OPORTUNISMO E RECEITAS}

\subsection{CPO pelo lado das receitas}

Quando se estudam os ciclos político-orçamentários é preciso observar o comportamento das variáveis que representam os anos com eleições e o ano subsequente. Como se está a analisar o oportunismo nas receitas, espera-se, de acordo com o proposto por Rogoff e Sibert (1988), que os coeficientes estimados para as variáveis Eleição $o_{t}$ e ApósEleição $o_{t}$ apresentem o sinal negativo e positivo, respectivamente, o que indica uma redução nas receitas em anos com votações e um aumento no ano seguinte.

Ao analisar as receitas públicas dos municípios brasileiros, percebe-se que as receitas próprias não são manipuladas em anos eleitorais. As receitas tributárias são reduzidas em anos eleitorais, bem como reduções no ano posterior aos pleitos. Por fim, as operações de crédito e as receitas advindas de alienações de património público não sofrem influência do oportunismo em anos com eleições. Ao passar a analise para as componentes da receita tributária (ITBI, ISS, IPTU e as taxas e tarifas), os resultados da Tabela 2 expõem uma evidente preferência por reduzir o IPTU, o ITBI e as taxas e tarifas, enquanto o ISS não é alterado em anos eleitorais.

Cabe lembrar que o IPTU é o imposto que incide sobre a propriedade de terrenos e edifícios urbanos, o ITBI sobre a transferência de imóveis e o ISS sobre a realização de serviços, desta forma fica evidente a preferência por reduzir o IPTU e o ITBI, que são impostos diretos e de muita visibilidade aos eleitores, quando comparado ao ISS. É importante também ressaltar que os Prefeitos podem não só baixar as alíquotas dos impostos, mas também aumentar as isenções e os benefícios fiscais em anos eleitorais ${ }^{12}$, o que também impacta na arrecadação.

\footnotetext{
${ }^{11}$ Hansen, L. P. (1982). Large sample properties of generalized method of moments estimator. Econometrica, 50(4), 1029-1054.

${ }^{12}$ Como base de comparação, segundo a Pesquisa de Informações Básicas Municipais 2015, em 2014, 966 municípios brasileiros utilizavam reduções do IPTU como benefício fiscal, já 1358 isentavam o IPTU para novos empreendimentos, 996 isentaram o ISS e 1210 não cobraram taxas e tarifas aos negócios que se instalassem no município.
} 
Outro ponto a ser salientado é que o IPTU é o imposto que apresenta o comportamento oportunista típico, conforme proposto por Rogoff e Sibert (1988), pois há queda no ano eleitoral e aumento no posterior. O ITBI e as taxas e tarifas são reduzidas em ambos os períodos e o ISS não sofre qualquer alteração.

Tabela 2: CPO nas componentes da receitas

\begin{tabular}{|c|c|c|c|c|c|c|c|c|}
\hline VARIABLES & $\begin{array}{c}\text { (1) } \\
\text { Rprop }\end{array}$ & $\begin{array}{c}(2) \\
\text { Tributos } \\
\end{array}$ & $\begin{array}{c}\text { (3) } \\
\text { ITBI }\end{array}$ & $\begin{array}{l}(4) \\
\text { ISS }\end{array}$ & $\begin{array}{c}(5) \\
\text { IPTU } \\
\end{array}$ & $\begin{array}{c}(6) \\
\text { Taxas }\end{array}$ & $\begin{array}{c}7) \\
\text { OCredito } \\
\end{array}$ & $\begin{array}{c}\text { (8) } \\
\text { Alienação }\end{array}$ \\
\hline Eleição & $\begin{array}{c}-0.000531 \\
(-0.579)\end{array}$ & $\begin{array}{c}-0.0890 * * * \\
(-14.75)\end{array}$ & $\begin{array}{c}-0.0691 * * * \\
(-4.495)\end{array}$ & $\begin{array}{c}-0.00360 \\
(-0.433)\end{array}$ & $\begin{array}{c}-0.141 * * * \\
(-6.376)\end{array}$ & $\begin{array}{c}-0.147 * * * \\
(-17.52)\end{array}$ & $\begin{array}{c}0.0669 \\
(0.0797)\end{array}$ & $\begin{array}{c}-0.416 \\
(-1.585)\end{array}$ \\
\hline ApósEleição & $\begin{array}{c}-0.00831 * * * \\
(-8.575)\end{array}$ & $\begin{array}{c}-0.0646 * * * \\
(-13.51)\end{array}$ & $\begin{array}{c}-0.0916 * * * \\
(-8.620)\end{array}$ & $\begin{array}{c}0.00646 \\
(0.774)\end{array}$ & $\begin{array}{c}0.0439 * \\
(1.769)\end{array}$ & $\begin{array}{c}-0.0650 * * * \\
(-7.185)\end{array}$ & $\begin{array}{c}-2.247 * * * \\
(-2.732)\end{array}$ & $\begin{array}{c}-0.349 \\
(-1.063)\end{array}$ \\
\hline PES15 & $\begin{array}{c}-0.499 * * * \\
(-7.366)\end{array}$ & $\begin{array}{c}-0.677 * * * \\
(-4.529)\end{array}$ & $\begin{array}{c}-0.754 * * \\
(-2.533)\end{array}$ & $\begin{array}{c}-1.290 * * * \\
(-6.014)\end{array}$ & $\begin{array}{c}1.299 \\
(1.398)\end{array}$ & $\begin{array}{c}-1.889 * * * \\
(-4.894)\end{array}$ & $\begin{array}{c}-6.149 \\
(-0.699)\end{array}$ & $\begin{array}{c}1.484 \\
(0.533)\end{array}$ \\
\hline PES65 & $\begin{array}{c}-0.860 * * * \\
(-6.415)\end{array}$ & $\begin{array}{l}-0.347^{*} \\
(-1.947)\end{array}$ & $\begin{array}{c}3.441 * * * \\
(3.786)\end{array}$ & $\begin{array}{c}-1.644 * * * \\
(-5.826)\end{array}$ & $\begin{array}{c}-2.734 \\
(-1.415)\end{array}$ & $\begin{array}{c}1.053 \\
(1.550)\end{array}$ & $\begin{array}{c}-6.295 \\
(-0.223)\end{array}$ & $\begin{array}{c}-2.785 \\
(-0.231)\end{array}$ \\
\hline Urbano & $\begin{array}{c}0.167 * * * \\
(13.51)\end{array}$ & $\begin{array}{c}0.181 * * * \\
(6.542)\end{array}$ & $\begin{array}{c}0.263 * * * \\
(4.375)\end{array}$ & $\begin{array}{c}0.215^{* * * *} \\
(8.518)\end{array}$ & $\begin{array}{l}-1.014^{*} \\
(-1.761)\end{array}$ & $\begin{array}{c}0.829 * * * \\
(13.39)\end{array}$ & $\begin{array}{l}-4.346 \\
(-0.917)\end{array}$ & $\begin{array}{c}0.580 \\
(0.274)\end{array}$ \\
\hline PIB & $\begin{array}{c}-0.000791 \\
(-0.177)\end{array}$ & $\begin{array}{c}0.160 * * * \\
(8.065)\end{array}$ & $\begin{array}{c}0.372 * * * \\
(5.332)\end{array}$ & $\begin{array}{c}0.216 * * * \\
(10.51)\end{array}$ & $\begin{array}{c}-0.112 \\
(-1.279)\end{array}$ & $\begin{array}{c}0.201 * * * \\
(9.525)\end{array}$ & $\begin{array}{c}1.384 \\
(0.628)\end{array}$ & $\begin{array}{c}-0.262 \\
(-0.373)\end{array}$ \\
\hline T_ANALF15M & $\begin{array}{c}-0.00488^{* * * *} \\
(-12.20)\end{array}$ & $\begin{array}{c}-0.00177 * * * \\
(-3.489)\end{array}$ & $\begin{array}{c}-0.0254 * * * \\
(-4.834)\end{array}$ & $\begin{array}{c}0.00313 * * * \\
\quad(4.204)\end{array}$ & $\begin{array}{l}0.0540^{*} \\
(1.726)\end{array}$ & $\begin{array}{c}-0.0440 * * * \\
(-17.75)\end{array}$ & $\begin{array}{l}-0.0677 \\
(-1.066)\end{array}$ & $\begin{array}{l}-0.0109 \\
(-0.855)\end{array}$ \\
\hline GINI & $\begin{array}{c}0.506 * * * \\
(12.90)\end{array}$ & $\begin{array}{c}0.335 * * * \\
(6.095)\end{array}$ & $\begin{array}{c}0.819 * * * \\
(4.199)\end{array}$ & $\begin{array}{c}0.468 * * * \\
(5.925)\end{array}$ & $\begin{array}{c}-0.951 \\
(-1.475)\end{array}$ & $\begin{array}{c}0.651 * * * \\
(3.644)\end{array}$ & $\begin{array}{l}-6.146^{*} \\
(-1.822)\end{array}$ & $\begin{array}{c}1.527 \\
(0.451)\end{array}$ \\
\hline$Y_{t-1}$ & $\begin{array}{c}0.244 * * * * \\
(10.28)\end{array}$ & $\begin{array}{c}0.764 * * * * \\
(29.04)\end{array}$ & $\begin{array}{c}0.528 * * * * \\
(5.995)\end{array}$ & $\begin{array}{c}0.767 * * * * \\
(45.28)\end{array}$ & $\begin{array}{c}1.512 * * * * \\
(5.074)\end{array}$ & $\begin{array}{c}0.341 * * * \\
(16.63)\end{array}$ & $\begin{array}{l}0.895^{* *} \\
(2.504)\end{array}$ & $\begin{array}{c}1.180 * * * \\
(4.602)\end{array}$ \\
\hline Constant & $\begin{array}{l}-0.0362 \\
(-0.960)\end{array}$ & $\begin{array}{c}0.742 * * * \\
(8.946)\end{array}$ & $\begin{array}{c}-0.186 \\
(-1.120)\end{array}$ & $\begin{array}{c}0.416 * * * \\
(5.811)\end{array}$ & $\begin{array}{c}-0.425 \\
(-1.142)\end{array}$ & $\begin{array}{c}1.004 * * * \\
(4.997)\end{array}$ & $\begin{array}{l}8.648^{* * *} \\
(2.385)\end{array}$ & $\begin{array}{c}-0.665 \\
(-0.275)\end{array}$ \\
\hline Observations & 24,508 & 24,508 & 24,508 & 24,508 & 24,508 & 24,508 & 24,508 & 24,508 \\
\hline $\begin{array}{l}\text { Number of } \\
\text { Codigo }\end{array}$ & 2,228 & 2,228 & 2,228 & 2,228 & 2,228 & 2,228 & 2,228 & 2,228 \\
\hline hansenp & 0.149 & 0.575 & 0.154 & 0.279 & 0.00201 & 0.353 & 0.719 & 0.537 \\
\hline $\operatorname{ar} 1 \mathrm{p}$ & 0 & 0 & 0 & 0 & $7.85 e-07$ & 0 & 0.000290 & 0.000379 \\
\hline $\operatorname{ar} 2 \mathrm{p}$ & 0.00296 & 0.00106 & 0.00112 & 0.147 & 0.000967 & 0.000931 & 0.00567 & 0.0136 \\
\hline
\end{tabular}

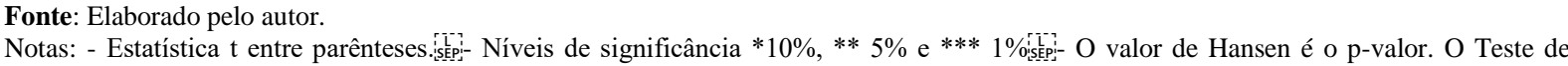
Hansen testa a exogeneidade dos instrumentos, sob a hipótese nula, de que os instrumentos são exógenos, esta estatística do teste segue a

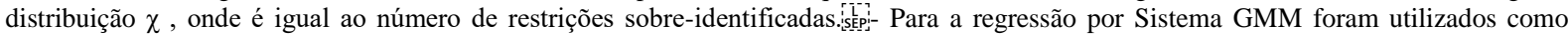
instrumentos as os defasamentos de todas as variáveis explicativas utilizadas em cada modelo, sendo que os desfasamentos variaram de 2 a 5. 5.

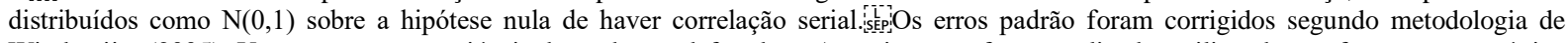
Windmeijer (2005). $\mathrm{Y}_{\mathrm{t}-1}$ representa as variáveis dependentes defasadas.- As estimações foram realizadas utilizando o software econométrico Stata $^{\circledR} 13$ for Mac.

Estes resultados indicam que os prefeitos brasileiros seguem um comportamento similar ao constatado por Katsimi e Sarantides (2012) e Morozumi, Veiga e Veiga (2014), pois reduzem o IPTU $(-14,1 \%)$ e o ITBI $(-6,91 \%)$, que são impostos diretos, e mantêm inalterados o imposto indireto ISS. Essa conduta expostas pelos resultados estimados é contraditória com as conclusões obtidas por Ehrhart (2013) para as nações em desenvolvimento, que constatou que há reduções nos impostos indiretos em anos eleitorais. As taxas e tarifas municipais, também são manipuladas, dado que as mesmas são reduzidas, conforme a coluna 6 da tabela 2, em $15 \%$ em anos eleitorais, esse resultado é diferente do de Klien (2014) que ao analisar a evolução das tarifas em Áustria constatou que os governantes evitam alterar essa componente em anos eleitorais e também de Reynolds (2014), que investigou o comportamento das mensalidades das universidades públicas estaduais norte-americanas e evidenciou que em 
anos com pleitos, as taxas universitárias são 1,5\% menores quando comparadas aos anos sem eleições. No caso brasileiro, as taxas e tarifas podem ser caracterizadas como tributos diretos, pois são pagas diretamente pela população e desta forma o seu comportamento em anos eleitorais é similar aos dos dois impostos diretos sobre a competência dos municípios brasileiros.

Tabela 3: Características dos prefeitos e as receitas públicas

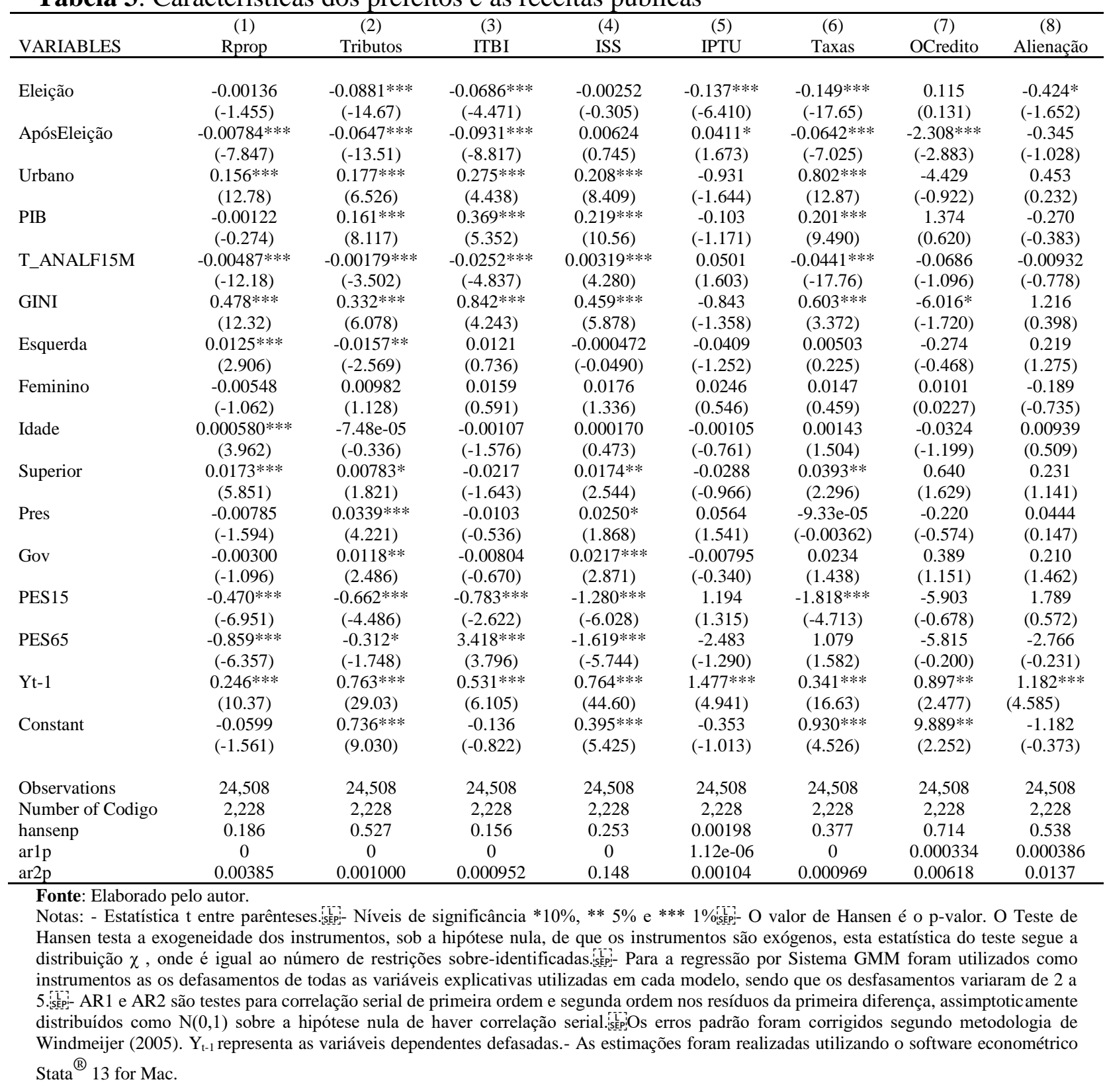

\subsection{Prefeitos e os níveis de receita}

Quando é analisado o impacto das características dos Prefeitos brasileiros sobre os níveis das receitas (tabela 3), percebe-se que os valores de receita própria são influenciados pela ideologia, idade e formação superior. Os prefeitos de esquerda, arrecadam menos com 
tributos que os demais, enquanto os municípios administrados por prefeitos com ensino superior, aliados do presidente da República e alinhados ao governador de estado, apresentam maiores níveis de receitas tributárias. As operações de crédito e as receitas advindas de alienação de património público não são influenciadas pelas características dos prefeitos brasileiros.

Já quando é analisado o impacto das características dos prefeitos sobre a arrendação dos diferentes tributos municipais, percebe-se que os Prefeitos com licenciatura apresentam maiores arrecadações de ISS e taxas e tarifas e o alinhamento político com Presidente da República e também ao Governador de Estado também tem influência no nível de recursos advindos do ISS. Por fim, o gênero não tem impacto sobre os níveis de receita.

\subsection{Condicionantes do oportunismo pelo lado das receitas}

Após ter sido investigada a relação entre as características dos Prefeitos brasileiros e os níveis de receita é interessante expandir a análise do impacto destas variáveis sobre o oportunismo pré-eleitoral. Para ser possível estudar o efeito condicionador das características dos prefeitos brasileiros no oportunismo é necessário gerar novas variáveis com a interação ${ }^{13}$ das características dos prefeitos ( Feminino $_{i, t}$, Superior $_{i, t}$, Idade $_{i, t}, E_{\text {squerda }}, t$, Pres $_{i, t}$ e $\operatorname{Gov}_{i, t}$ ) com a variável Eleição $o_{t}$. Desta forma, quando forem analisadas a soma dos coeficientes estimados para as interações com o da variável Eleição $o_{t}$ será possível constatar se a referida característica do prefeito tem ou não impacto no comportamento oportunista.

O teste de Wald $^{14}$ possui um papel fundamental nessa análise, pois ele testa para a combinação linear entre as variável Eleição $_{t}$ e as interações $\left(F_{\text {eminino }} E_{i, t}\right.$, Superior $E_{i, t}$, $\operatorname{Idade}_{i, t}, E_{s q u e r d a E_{i, t}}, \operatorname{Pres}_{i, t}$ e $\left.\operatorname{Gov}_{i, t}\right)$. Caso não se possa rejeitar a hipótese nula, significa que a soma dos coeficientes estimados é zero e desta forma o efeito não é significativo.

\footnotetext{
${ }^{13}$ Multiplica-se a variável que representa a característica do prefeito com a variável Eleição.

${ }^{14} \mathrm{O}$ teste de Wald tem como hipótese nula que $\beta_{1}-\beta_{2}=0$ e segue a distribuição $F$ com $J$ restrições e $N$ - $K$ graus de liberdade (Verbeek, p.30, 2008).
} 
Tabela 4: Receitas próprias

\begin{tabular}{|c|c|c|c|c|c|c|}
\hline VARIABLES & $\begin{array}{l}(1) \\
\text { FemininoE }\end{array}$ & $\begin{array}{l}(2) \\
\text { EsquerdaE }\end{array}$ & $\begin{array}{l}3) \\
\text { IdadeE }\end{array}$ & $\begin{array}{l}(4) \\
\text { SuperiorE }\end{array}$ & $\begin{array}{l}\text { (5) } \\
\text { PresE }\end{array}$ & $\begin{array}{l}\text { (6) } \\
\text { GovE }\end{array}$ \\
\hline Eleição & $\begin{array}{l}-0.00127 \\
(-1.291)\end{array}$ & $\begin{array}{l}-0.00104 \\
(-0.984)\end{array}$ & $\begin{array}{l}0.00127 \\
(0.281)\end{array}$ & $\begin{array}{l}-0.00301 \text { ** } \\
(-2.232)\end{array}$ & $\begin{array}{l}-0.00138 \\
(-1.377)\end{array}$ & $\begin{array}{l}-0.00150 \\
(-1.342)\end{array}$ \\
\hline Esquerda & $\begin{array}{l}0.0125^{* * * *} \\
(2.905)\end{array}$ & $\begin{array}{l}0.0129 * * * * \\
(2.992)\end{array}$ & $\begin{array}{l}0.0125^{* * * *} \\
(2.904)\end{array}$ & $\begin{array}{l}0.0125^{* * * *} \\
(2.913)\end{array}$ & $\begin{array}{l}0.0125^{* * * *} \\
(2.897)\end{array}$ & $\begin{array}{l}0.0125 * * * \\
(2.904)\end{array}$ \\
\hline Feminino & $\begin{array}{l}-0.00508 \\
(-0.975)\end{array}$ & $\begin{array}{l}-0.00547 \\
(-1.061)\end{array}$ & $\begin{array}{l}-0.00547 \\
(-1.060)\end{array}$ & $\begin{array}{l}-0.00551 \\
(-1.070)\end{array}$ & $\begin{array}{l}-0.00548 \\
(-1.063)\end{array}$ & $\begin{array}{l}-0.00548 \\
(-1.063)\end{array}$ \\
\hline Idade & $\begin{array}{l}0.000580^{* * * *} \\
(3.962)\end{array}$ & $\begin{array}{l}0.000580^{* * *} \\
(3.962)\end{array}$ & $\begin{array}{l}0.000593^{* * * *} \\
(3.978)\end{array}$ & $\begin{array}{l}0.000579 * * * \\
(3.963)\end{array}$ & $\begin{array}{l}0.000580^{* * * *} \\
(3.963)\end{array}$ & $\begin{array}{l}0.000580 \text { *** } \\
(3.963)\end{array}$ \\
\hline Superior & $\begin{array}{l}0.0173 * * * \\
(5.851)\end{array}$ & $\begin{array}{l}0.0173 * * * \\
(5.850)\end{array}$ & $\begin{array}{l}0.0173^{* * * *} \\
(5.849)\end{array}$ & $\begin{array}{l}0.0163^{* * *} \\
(5.503)\end{array}$ & $\begin{array}{l}0.0173^{* * * *} \\
(5.851)\end{array}$ & $\begin{array}{l}0.0173 * * * \\
(5.851)\end{array}$ \\
\hline Pres & $\begin{array}{l}-0.00785 \\
(-1.593)\end{array}$ & $\begin{array}{l}-0.00782 \\
(-1.585)\end{array}$ & $\begin{array}{l}-0.00785 \\
(-1.593)\end{array}$ & $\begin{array}{l}-0.00786 \\
(-1.596)\end{array}$ & $\begin{array}{l}-0.00788 \\
(-1.621)\end{array}$ & $\begin{array}{l}-0.00785 \\
(-1.592)\end{array}$ \\
\hline Gov & $\begin{array}{l}-0.00300 \\
(-1.096)\end{array}$ & $\begin{array}{l}-0.00299 \\
(-1.092)\end{array}$ & $\begin{array}{l}-0.00300 \\
(-1.098)\end{array}$ & $\begin{array}{l}-0.00298 \\
(-1.090)\end{array}$ & $\begin{array}{l}-0.00300 \\
(-1.097)\end{array}$ & $\begin{array}{l}-0.00317 \\
(-1.138)\end{array}$ \\
\hline FemininoE & $\begin{array}{l}-0.00149 \\
(-0.496)\end{array}$ & & & & & \\
\hline EsquerdaE & & $\begin{array}{l}-0.00171 \\
(-0.800)\end{array}$ & & & & \\
\hline IdadeE & & & $\begin{array}{l}-5.07 e-05 \\
(-0.591)\end{array}$ & & & \\
\hline SuperiorE & & & & $\begin{array}{l}0.00347^{*} \\
(1.933)\end{array}$ & & \\
\hline PresE & & & & & $\begin{array}{l}0.000180 \\
(0.0563)\end{array}$ & \\
\hline GovE & & & & & & $\begin{array}{l}0.000678 \\
(0.280)\end{array}$ \\
\hline Observations & 24,508 & 24,508 & 24,508 & 24,508 & 24,508 & 24,508 \\
\hline Number of Codigo & 2,228 & 2,228 & 2,228 & 2,228 & 2,228 & 2,228 \\
\hline Teste de Wald & 0.9491 & 0.8103 & 0.7740 & 0.0269 & 0.6726 & 0.4939 \\
\hline hansenp & 0.186 & 0.185 & 0.185 & 0.197 & 0.186 & 0.186 \\
\hline $\operatorname{ar} 1 \mathrm{p}$ & 0 & 0 & 0 & 0 & 0 & 0 \\
\hline $\operatorname{ar} 2 p$ & 0.00385 & 0.00402 & 0.00388 & 0.00358 & 0.00380 & 0.00388 \\
\hline
\end{tabular}

Fonte: Elaborado pelo autor.

Notas: - Estatística t entre parênteses. Hansen testa a exogeneidade dos instrumentos, sob a hipótese nula, de que os instrumentos são exógenos, esta estatística do teste segue a distribuição $\chi$, onde é igual ao número de restrições sobre-identificadas. instrumentos as os defasamentos de todas as variáveis explicativas utilizadas em cada modelo, sendo que os desfasamentos variaram de 2 a 5. TLE- AR1 e AR2 são testes para correlação serial de primeira ordem e segunda ordem nos resíduos da primeira diferença, assimptoticamente distribuídos como $\mathrm{N}(0,1)$ sobre a hipótese nula de haver correlação serial.sế Os erros padrão foram corrigidos segundo metodologia de Windmeijer (2005). $\mathrm{Y}_{\mathrm{t}-1}$ representa as variáveis dependentes defasadas. -As variáveis explicativas AposEleição, Urbano, PES15, PES65, $P I B, T \_A N A L F 15 M$ e GINI foram mantidas em todas as estimações, mas os resultados foram retirados pela questão do espaço- As estimações foram realizadas utilizando o software econométrico Stata ${ }^{\circledR} 13$ for Mac.

Quando são analisadas as características dos governantes como condicionantes do oportunismo nas receitas próprias, apercebe-se que, segundo os resultados contidos na tabela 4, o fato do Prefeito possuir o ensino superior completo implica num aumento de $0,046 \% 15$ em anos eleitorais, contudo esse aumento é muito próximo de zero.

\footnotetext{
${ }^{15} \mathrm{O}$ valor $0,046 \%$ é obtido pela soma dos coeficientes estimados para a variável Eleição $o_{t}$ a interação Superior $_{i, t}[(-0.00301)+(0.0254)]=$ 0,046 .
} 
Tabela 5: Receitas tributária

\begin{tabular}{|c|c|c|c|c|c|c|}
\hline VARIABLES & $\begin{array}{l}(1) \\
\text { FemininoE }\end{array}$ & $\begin{array}{l}\text { (2) } \\
\text { EsquerdaE }\end{array}$ & $\begin{array}{l}3) \\
\text { IdadeE }\end{array}$ & $\begin{array}{l}(4) \\
\text { SuperiorE }\end{array}$ & $\begin{array}{l}5) \\
\text { PresE }\end{array}$ & $\begin{array}{l}6) \\
\text { GovE }\end{array}$ \\
\hline Eleição & $\begin{array}{l}-0.0874 * * * \\
(-14.41)\end{array}$ & $\begin{array}{l}-0.0908 * * * \\
(-14.30)\end{array}$ & $\begin{array}{l}-0.144 * * * \\
(-5.965)\end{array}$ & $\begin{array}{l}-0.100 * * * \\
(-13.90)\end{array}$ & $\begin{array}{l}-0.0857 * * * \\
(-14.07)\end{array}$ & $\begin{array}{l}-0.0888^{* * * *} \\
(-14.16)\end{array}$ \\
\hline Esquerda & $\begin{array}{l}-0.0158 * * \\
(-2.572)\end{array}$ & $\begin{array}{l}-0.0196^{* * * *} \\
(-2.922)\end{array}$ & $\begin{array}{l}-0.0157 * * \\
(-2.566)\end{array}$ & $\begin{array}{l}-0.0157 * * \\
(-2.555)\end{array}$ & $\begin{array}{l}-0.0150 * * \\
(-2.449)\end{array}$ & $\begin{array}{l}-0.0158 * * \\
(-2.572)\end{array}$ \\
\hline Feminino & $\begin{array}{l}0.0126 \\
(1.182)\end{array}$ & $\begin{array}{l}0.00986 \\
(1.131)\end{array}$ & $\begin{array}{l}0.00985 \\
(1.132)\end{array}$ & $\begin{array}{l}0.00998 \\
(1.145)\end{array}$ & $\begin{array}{l}0.00980 \\
(1.127)\end{array}$ & $\begin{array}{l}0.00982 \\
(1.128)\end{array}$ \\
\hline Idade & $\begin{array}{l}-7.53 e-05 \\
(-0.339)\end{array}$ & $\begin{array}{l}-7.39 e-05 \\
(-0.332)\end{array}$ & $\begin{array}{l}-0.000368 \\
(-1.439)\end{array}$ & $\begin{array}{l}-6.96 e-05 \\
(-0.313)\end{array}$ & $\begin{array}{l}-7.89 \mathrm{e}-05 \\
(-0.355)\end{array}$ & $\begin{array}{l}-7.44 \mathrm{e}-05 \\
(-0.335)\end{array}$ \\
\hline Superior & $\begin{array}{l}0.00783^{*} \\
(1.820)\end{array}$ & $\begin{array}{l}0.00787^{*} \\
(1.828)\end{array}$ & $\begin{array}{l}0.00786^{*} \\
(1.826)\end{array}$ & $\begin{array}{l}0.000929 \\
(0.188)\end{array}$ & $\begin{array}{l}0.00783 * \\
(1.822)\end{array}$ & $\begin{array}{l}0.00784^{*} \\
(1.822)\end{array}$ \\
\hline Pres & $\begin{array}{l}0.0339 * * * \\
(4.224)\end{array}$ & $\begin{array}{l}0.0335^{* * * *} \\
(4.163)\end{array}$ & $\begin{array}{l}0.0338^{* * * *} \\
(4.224)\end{array}$ & $\begin{array}{l}0.0338 * * * \\
(4.210)\end{array}$ & $\begin{array}{l}0.0397 * * * \\
(4.339)\end{array}$ & $\begin{array}{l}0.0339 * * * \\
(4.222)\end{array}$ \\
\hline Gov & $\begin{array}{l}0.0118^{* *} \\
(2.484)\end{array}$ & $\begin{array}{l}0.0117 * * \\
(2.465)\end{array}$ & $\begin{array}{l}0.0119 * * \\
(2.508)\end{array}$ & $\begin{array}{l}0.0119 * * \\
(2.499)\end{array}$ & $\begin{array}{l}0.0119 * * \\
(2.507)\end{array}$ & $\begin{array}{l}0.0109^{*} \\
(1.887)\end{array}$ \\
\hline FemininoE & $\begin{array}{l}-0.0102 \\
(-0.496)\end{array}$ & & & & & \\
\hline EsquerdaE & & $\begin{array}{l}0.0147 \\
(1.358)\end{array}$ & & & & \\
\hline IdadeE & & & $\begin{array}{l}0.00108 * * \\
(2.419)\end{array}$ & & & \\
\hline SuperiorE & & & & $\begin{array}{l}0.0254 * * * \\
(3.159)\end{array}$ & & \\
\hline PresE & & & & & $\begin{array}{l}-0.0266^{*} \\
(-1.770)\end{array}$ & \\
\hline GovE & & & & & & $\begin{array}{l}0.00362 \\
(0.327)\end{array}$ \\
\hline Observations & 24,508 & 24,508 & 24,508 & 24,508 & 24,508 & 24,508 \\
\hline Number of Codigo & 2,228 & 2,228 & 2,228 & 2,228 & 2,228 & 2,228 \\
\hline Teste de Wald & 0.0006 & 0.0000 & 0.0000 & 0.0000 & 0.0006 & 0.0000 \\
\hline hansenp & 0.542 & 0.501 & 0.473 & 0.398 & 0.608 & 0.533 \\
\hline $\operatorname{ar} 1 \mathrm{p}$ & 0 & 0 & 0 & 0 & 0 & 0 \\
\hline $\operatorname{ar} 2 \mathrm{p}$ & 0.000995 & 0.000971 & 0.00100 & 0.000954 & 0.00103 & 0.000989 \\
\hline
\end{tabular}

Fonte: Elaborado pelo autor.

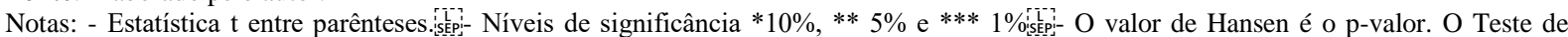
Hansen testa a exogeneidade dos instrumentos, sob a hipótese nula, de que os instrumentos são exógenos, esta estatística do teste segue a distribuição $\chi$, onde é igual ao número de restrições sobre-identificadas. instrumentos as os defasamentos de todas as variáveis explicativas utilizadas em cada modelo, sendo que os desfasamentos variaram de 2 a 5. distribuídos como $\mathrm{N}(0,1)$ sobre a hipótese nula de haver correlação serial.sế Os erros padrão foram corrigidos segundo metodologia de Windmeijer (2005). $\mathrm{Y}_{\mathrm{t}-1}$ representa as variáveis dependentes defasadas. -As variáveis explicativas AposEleição, Urbano, PES15, PES65, PIB, T_ANALF15M e GINI foram mantidas em todas as estimações, mas os resultados foram retirados pela questão do espaço- As estimações foram realizadas utilizando o software econométrico Stata ${ }^{\circledR} 13$ for Mac.

Quando se passa a analisar as receitas tributárias, percebe-se, conforme os resultados contidos na tabela 5, que a idade do Prefeito apresenta um impacto redutor do oportunismo préeleitoral nos tributos. Na mesma direção os governantes locais com formação superior reduzem menos as receitas tributárias em anos com eleições, quando comparados aos sem formação superior, tudo o resto igual, contudo, mesmo assim a redução é de $7,46 \%$. Na direção oposta, há os prefeitos aliados ao Presidente da República, que em anos com votações reduzem ainda mais as receitas advindas de tributos $(-11,23 \%)$. 
Tabela 6: Operações de crédito

\begin{tabular}{|c|c|c|c|c|c|c|}
\hline VARIABLES & $\begin{array}{l}(1) \\
\text { FemininoE }\end{array}$ & $\begin{array}{l}(2) \\
\text { EsquerdaE }\end{array}$ & $\begin{array}{l}\text { (3) } \\
\text { IdadeE }\end{array}$ & $\begin{array}{l}(4) \\
\text { SuperiorE }\end{array}$ & $\begin{array}{l}5) \\
\text { PresE }\end{array}$ & $\begin{array}{l}\text { (6) } \\
\text { GovE }\end{array}$ \\
\hline Eleição & $\begin{array}{l}0.0291 \\
(0.0324)\end{array}$ & $\begin{array}{l}0.585 \\
(0.694)\end{array}$ & $\begin{array}{l}0.173 \\
(0.0448)\end{array}$ & $\begin{array}{l}-0.673 \\
(-0.665)\end{array}$ & $\begin{array}{l}0.273 \\
(0.328)\end{array}$ & $\begin{array}{l}-0.237 \\
(-0.261)\end{array}$ \\
\hline Esquerda & $\begin{array}{l}-0.274 \\
(-0.467)\end{array}$ & $\begin{array}{l}0.392 \\
(0.643)\end{array}$ & $\begin{array}{l}-0.274 \\
(-0.467)\end{array}$ & $\begin{array}{l}-0.274 \\
(-0.467)\end{array}$ & $\begin{array}{l}-0.217 \\
(-0.379)\end{array}$ & $\begin{array}{l}-0.297 \\
(-0.505)\end{array}$ \\
\hline Feminino & $\begin{array}{l}-0.346 \\
(-0.613)\end{array}$ & $\begin{array}{l}0.0154 \\
(0.0344)\end{array}$ & $\begin{array}{l}0.00997 \\
(0.0224)\end{array}$ & $\begin{array}{l}0.0133 \\
(0.0298)\end{array}$ & $\begin{array}{l}0.0153 \\
(0.0343)\end{array}$ & $\begin{array}{l}0.0154 \\
(0.0346)\end{array}$ \\
\hline Idade & $\begin{array}{l}-0.0324 \\
(-1.197)\end{array}$ & $\begin{array}{l}-0.0320 \\
(-1.172)\end{array}$ & $\begin{array}{l}-0.0321 \\
(-1.181)\end{array}$ & $\begin{array}{l}-0.0322 \\
(-1.192)\end{array}$ & $\begin{array}{l}-0.0325 \\
(-1.201)\end{array}$ & $\begin{array}{l}-0.0317 \\
(-1.169)\end{array}$ \\
\hline Superior & $\begin{array}{l}0.639 \\
(1.628)\end{array}$ & $\begin{array}{l}0.631 \\
(1.592)\end{array}$ & $\begin{array}{l}0.640 \\
(1.628)\end{array}$ & $\begin{array}{l}0.187 \\
(0.427)\end{array}$ & $\begin{array}{l}0.640 \\
(1.629)\end{array}$ & $\begin{array}{l}0.634 \\
(1.609)\end{array}$ \\
\hline Pres & $\begin{array}{l}-0.222 \\
(-0.580)\end{array}$ & $\begin{array}{l}-0.166 \\
(-0.430)\end{array}$ & $\begin{array}{l}-0.220 \\
(-0.574)\end{array}$ & $\begin{array}{l}-0.221 \\
(-0.577)\end{array}$ & $\begin{array}{l}0.176 \\
(0.264)\end{array}$ & $\begin{array}{l}-0.211 \\
(-0.552)\end{array}$ \\
\hline Gov & $\begin{array}{l}0.390 \\
(1.153)\end{array}$ & $\begin{array}{l}0.409 \\
(1.210)\end{array}$ & $\begin{array}{l}0.389 \\
(1.150)\end{array}$ & $\begin{array}{l}0.391 \\
(1.156)\end{array}$ & $\begin{array}{l}0.398 \\
(1.177)\end{array}$ & $\begin{array}{l}-0.0264 \\
(-0.0549)\end{array}$ \\
\hline FemininoE & $\begin{array}{l}1.329 \\
(0.682)\end{array}$ & & & & & \\
\hline EsquerdaE & & $\begin{array}{l}-2.578 \\
(-1.415)\end{array}$ & & & & \\
\hline IdadeE & & & $\begin{array}{c}-0.00112 \\
(-0.0168)\end{array}$ & & & \\
\hline SuperiorE & & & & $\begin{array}{l}1.657 \\
(1.309)\end{array}$ & & \\
\hline PresE & & & & & $\begin{array}{l}-1.846 \\
(-0.659)\end{array}$ & \\
\hline GovE & & & & & & $\begin{array}{l}1.610 \\
(1.138)\end{array}$ \\
\hline Observations & 24,508 & 24,508 & 24,508 & 24,508 & 24,508 & 24,508 \\
\hline Number of Codigo & 2,228 & 2,228 & 2,228 & 2,228 & 2,228 & 2,228 \\
\hline Teste de Wald & 0.5803 & 0.1275 & 0.9646 & 0.2403 & 0.4631 & 0.3233 \\
\hline hansenp & 0.714 & 0.707 & 0.714 & 0.720 & 0.710 & 0.715 \\
\hline arlp & 0.000334 & 0.000368 & 0.000345 & 0.000330 & 0.000346 & 0.000329 \\
\hline $\operatorname{ar} 2 p$ & 0.00616 & 0.00640 & 0.00630 & 0.00610 & 0.00628 & 0.00594 \\
\hline
\end{tabular}

Fonte: Elaborado pelo autor.

Notas: - Estatística t entre parênteses. Hansen testa a exogeneidade dos instrumentos, sob a hipótese nula, de que os instrumentos são exógenos, esta estatística do teste segue a distribuição $\chi$, onde é igual ao número de restrições sobre-identificadas. instrumentos as os defasamentos de todas as variáveis explicativas utilizadas em cada modelo, sendo que os desfasamentos variaram de 2 a 5. T- A - AR1 e AR2 são testes para correlação serial de primeira ordem e segunda ordem nos resíduos da primeira diferença, assimptoticamente distribuídos como $\mathrm{N}(0,1)$ sobre a hipótese nula de haver correlação serial.sế Os erros padrão foram corrigidos segundo metodologia de Windmeijer (2005). $\mathrm{Y}_{\mathrm{t}-1}$ representa as variáveis dependentes defasadas. -As variáveis explicativas AposEleição, Urbano, PES15, PES65, $P I B, T \_A N A L F 15 M$ e GINI foram mantidas em todas as estimações, mas os resultados foram retirados pela questão do espaço- As estimações foram realizadas utilizando o software econométrico Stata ${ }^{\circledR} 13$ for Mac.

Nenhuma das características dos prefeitos analisadas parece influenciar nos níveis de operações de créditos em anos eleitorais. Esse comportamento, exposto na tabela 6 , já era esperado, pois a legislação eleitoral brasileira e a LRF são muito rígidas no que tange essas operações em anos eleitorais, o que dificulta a manipulação dessa fonte de recursos em anos eleitorais. 
Tabela 7: Alienação

\begin{tabular}{|c|c|c|c|c|c|c|}
\hline VARIABLES & $\begin{array}{l}\text { (1) } \\
\text { FemininoE }\end{array}$ & $\begin{array}{l}\text { (2) } \\
\text { EsquerdaE }\end{array}$ & $\begin{array}{l}\text { (3) } \\
\text { IdadeE }\end{array}$ & $\begin{array}{l}\text { (4) } \\
\text { SuperiorE }\end{array}$ & $\begin{array}{l}(5) \\
\text { PresE }\end{array}$ & $\begin{array}{l}\text { (6) } \\
\text { GovE }\end{array}$ \\
\hline Eleição & $\begin{array}{l}-0.382 \\
(-1.408)\end{array}$ & $\begin{array}{l}-0.333 \\
(-1.075)\end{array}$ & $\begin{array}{l}-3.497 * * \\
(-2.130)\end{array}$ & $\begin{array}{l}-0.677 * \\
(-1.817)\end{array}$ & $\begin{array}{l}-0.346 \\
(-1.252)\end{array}$ & $\begin{array}{l}-0.678 * * \\
(-2.322)\end{array}$ \\
\hline Esquerda & $\begin{array}{l}0.218 \\
(1.276)\end{array}$ & $\begin{array}{l}0.346^{*} \\
(1.883)\end{array}$ & $\begin{array}{l}0.217 \\
(1.260)\end{array}$ & $\begin{array}{l}0.218 \\
(1.271)\end{array}$ & $\begin{array}{l}0.247 \\
(1.459)\end{array}$ & $\begin{array}{l}0.207 \\
(1.198)\end{array}$ \\
\hline Feminino & $\begin{array}{l}-0.0126 \\
(-0.0516)\end{array}$ & $\begin{array}{l}-0.190 \\
(-0.736)\end{array}$ & $\begin{array}{l}-0.185 \\
(-0.711)\end{array}$ & $\begin{array}{l}-0.187 \\
(-0.723)\end{array}$ & $\begin{array}{l}-0.188 \\
(-0.730)\end{array}$ & $\begin{array}{l}-0.186 \\
(-0.717)\end{array}$ \\
\hline Idade & $\begin{array}{l}0.00933 \\
(0.506)\end{array}$ & $\begin{array}{l}0.00937 \\
(0.508)\end{array}$ & $\begin{array}{l}-0.00629 \\
(-0.322)\end{array}$ & $\begin{array}{l}0.00960 \\
(0.519)\end{array}$ & $\begin{array}{l}0.00925 \\
(0.502)\end{array}$ & $\begin{array}{l}0.00993 \\
(0.537)\end{array}$ \\
\hline Superior & $\begin{array}{l}0.231 \\
(1.138)\end{array}$ & $\begin{array}{l}0.231 \\
(1.139)\end{array}$ & $\begin{array}{l}0.236 \\
(1.162)\end{array}$ & $\begin{array}{l}0.0881 \\
(0.398)\end{array}$ & $\begin{array}{l}0.231 \\
(1.141)\end{array}$ & $\begin{array}{l}0.235 \\
(1.159)\end{array}$ \\
\hline Pres & $\begin{array}{l}0.0447 \\
(0.148)\end{array}$ & $\begin{array}{l}0.0543 \\
(0.178)\end{array}$ & $\begin{array}{l}0.0503 \\
(0.166)\end{array}$ & $\begin{array}{l}0.0464 \\
(0.154)\end{array}$ & $\begin{array}{l}0.237 \\
(0.697)\end{array}$ & $\begin{array}{l}0.0569 \\
(0.187)\end{array}$ \\
\hline Gov & $\begin{array}{l}0.210 \\
(1.461)\end{array}$ & $\begin{array}{l}0.213 \\
(1.487)\end{array}$ & $\begin{array}{l}0.214 \\
(1.490)\end{array}$ & $\begin{array}{l}0.210 \\
(1.463)\end{array}$ & $\begin{array}{l}0.214 \\
(1.493)\end{array}$ & $\begin{array}{l}-0.104 \\
(-0.520)\end{array}$ \\
\hline FemininoE & $\begin{array}{l}-0.662 \\
(-0.914)\end{array}$ & & & & & \\
\hline EsquerdaE & & $\begin{array}{l}-0.488 \\
(-0.739)\end{array}$ & & & & \\
\hline IdadeE & & & $\begin{array}{l}0.0592 * * \\
(1.974)\end{array}$ & & & \\
\hline SuperiorE & & & & $\begin{array}{l}0.531 \\
(1.018)\end{array}$ & & \\
\hline PresE & & & & & $\begin{array}{l}-0.902 \\
(-1.074)\end{array}$ & \\
\hline GovE & & & & & & $\begin{array}{l}1.212 * * \\
(2.018)\end{array}$ \\
\hline Observations & 24,508 & 24,508 & 24,508 & 24,508 & 24,508 & 24,508 \\
\hline Number of Codigo & 2,228 & 2,228 & 2,228 & 2,228 & 2,228 & 2,228 \\
\hline Teste Wald & 0.7472 & 0.8602 & 0.0335 & 0.1469 & 0.5706 & 0.0158 \\
\hline hansenp & 0.537 & 0.537 & 0.540 & 0.537 & 0.538 & 0.540 \\
\hline $\operatorname{ar} 1 \mathrm{p}$ & 0.000385 & 0.000384 & 0.000381 & 0.000385 & 0.000384 & 0.000383 \\
\hline $\operatorname{ar} 2 \mathrm{p}$ & 0.0137 & 0.0136 & 0.0135 & 0.0136 & 0.0137 & 0.0135 \\
\hline
\end{tabular}

Fonte: Elaborado pelo autor.

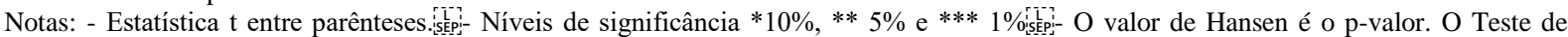
Hansen testa a exogeneidade dos instrumentos, sob a hipótese nula, de que os instrumentos são exógenos, esta estatística do teste segue a distribuição $\chi$, onde é igual ao número de restrições sobre-identificadas. instrumentos as os defasamentos de todas as variáveis explicativas utilizadas em cada modelo, sendo que os desfasamentos variaram de 2 a 5. distribuídos como $\mathrm{N}(0,1)$ sobre a hipótese nula de haver correlação serial.jș Windmeijer (2005). $\mathrm{Y}_{\mathrm{t}-1}$ representa as variáveis dependentes defasadas. -As variáveis explicativas AposEleição, Urbano, PES15, PES65, $P I B, T \_A N A L F 15 M$ e GINI foram mantidas em todas as estimações, mas os resultados foram retirados pela questão do espaço- As estimações foram realizadas utilizando o software econométrico Stata ${ }^{\circledR} 13$ for Mac.

Quando se analisam as receitas de alienações de património público, em anos eleitorais, percebe-se, segundo os resultados expostos na tabela 7, que os prefeitos do mesmo partido dos Governadores de estado, apresentam elevação de 53,4\% nas alienações em anos com votação, quando comparados aos demais. 
Tabela 8: Receitas IPTU

\begin{tabular}{|c|c|c|c|c|c|c|}
\hline VARIABLES & $\begin{array}{l}\text { (1) } \\
\text { FemininoE }\end{array}$ & $\begin{array}{l}\text { (2) } \\
\text { EsquerdaE }\end{array}$ & $\begin{array}{l}\text { (3) } \\
\text { IdadeE }\end{array}$ & $\begin{array}{l}\text { (4) } \\
\text { SuperiorE }\end{array}$ & $\begin{array}{l}(5) \\
\text { PresE }\end{array}$ & $\begin{array}{l}\text { (6) } \\
\text { GovE }\end{array}$ \\
\hline Eleição & $\begin{array}{l}-0.133 * * * \\
(-6.532)\end{array}$ & $\begin{array}{l}-0.142 * * * \\
(-6.415)\end{array}$ & $\begin{array}{l}-0.110 \\
(-1.561)\end{array}$ & $\begin{array}{l}-0.134 * * * \\
(-6.518)\end{array}$ & $\begin{array}{l}-0.138 * * * \\
(-6.327)\end{array}$ & $\begin{array}{l}-0.143 * * * \\
(-6.665)\end{array}$ \\
\hline Esquerda & $\begin{array}{l}-0.0409 \\
(-1.256)\end{array}$ & $\begin{array}{l}-0.0469 \\
(-1.420)\end{array}$ & $\begin{array}{l}-0.0400 \\
(-1.231)\end{array}$ & $\begin{array}{l}-0.0384 \\
(-1.183)\end{array}$ & $\begin{array}{l}-0.0412 \\
(-1.262)\end{array}$ & $\begin{array}{l}-0.0410 \\
(-1.258)\end{array}$ \\
\hline Feminino & $\begin{array}{l}0.0440 \\
(0.871)\end{array}$ & $\begin{array}{l}0.0244 \\
(0.545)\end{array}$ & $\begin{array}{l}0.0235 \\
(0.525)\end{array}$ & $\begin{array}{l}0.0227 \\
(0.512)\end{array}$ & $\begin{array}{l}0.0247 \\
(0.550)\end{array}$ & $\begin{array}{l}0.0246 \\
(0.546)\end{array}$ \\
\hline Idade & $\begin{array}{l}-0.00105 \\
(-0.764)\end{array}$ & $\begin{array}{l}-0.00103 \\
(-0.755)\end{array}$ & $\begin{array}{l}-0.000871 \\
(-0.619)\end{array}$ & $\begin{array}{l}-0.000941 \\
(-0.690)\end{array}$ & $\begin{array}{l}-0.00104 \\
(-0.760)\end{array}$ & $\begin{array}{l}-0.00104 \\
(-0.757)\end{array}$ \\
\hline Superior & $\begin{array}{l}-0.0289 \\
(-0.971)\end{array}$ & $\begin{array}{l}-0.0284 \\
(-0.955)\end{array}$ & $\begin{array}{l}-0.0276 \\
(-0.926)\end{array}$ & $\begin{array}{l}-0.0251 \\
(-0.879)\end{array}$ & $\begin{array}{l}-0.0289 \\
(-0.973)\end{array}$ & $\begin{array}{l}-0.0288 \\
(-0.965)\end{array}$ \\
\hline Pres & $\begin{array}{l}0.0565 \\
(1.549)\end{array}$ & $\begin{array}{l}0.0553 \\
(1.516)\end{array}$ & $\begin{array}{l}0.0560 \\
(1.541)\end{array}$ & $\begin{array}{l}0.0551 \\
(1.528)\end{array}$ & $\begin{array}{l}0.0553 \\
(1.497)\end{array}$ & $\begin{array}{l}0.0565 \\
(1.545)\end{array}$ \\
\hline Gov & $\begin{array}{l}-0.00803 \\
(-0.344)\end{array}$ & $\begin{array}{l}-0.00797 \\
(-0.343)\end{array}$ & $\begin{array}{l}-0.00722 \\
(-0.310)\end{array}$ & $\begin{array}{l}-0.00637 \\
(-0.275)\end{array}$ & $\begin{array}{l}-0.00815 \\
(-0.349)\end{array}$ & $\begin{array}{l}-0.0149 \\
(-0.614)\end{array}$ \\
\hline FemininoE & $\begin{array}{l}-0.0698 \\
(-1.274)\end{array}$ & & & & & \\
\hline EsquerdaE & & $\begin{array}{l}0.0244 \\
(0.854)\end{array}$ & & & & \\
\hline IdadeE & & & $\begin{array}{l}-0.000510 \\
(-0.375)\end{array}$ & & & \\
\hline SuperiorE & & & & $\begin{array}{l}-0.00207 \\
(-0.0836)\end{array}$ & & \\
\hline PresE & & & & & $\begin{array}{l}0.00560 \\
(0.152)\end{array}$ & \\
\hline GovE & & & & & & $\begin{array}{l}0.0266 \\
(0.870)\end{array}$ \\
\hline Observations & 24,508 & 24,508 & 24,508 & 24,508 & 24,508 & 24,508 \\
\hline Number of Codigo & 2,228 & 2,228 & 2,228 & 2,228 & 2,228 & 2,228 \\
\hline Teste Wald & 0.2402 & 0.0000 & 0.1272 & 0.0001 & 0.0021 & 0.0000 \\
\hline hansenp & 0.00188 & 0.00201 & 0.00174 & 0.00164 & 0.00196 & 0.00197 \\
\hline $\operatorname{ar} 1 \mathrm{p}$ & $1.15 \mathrm{e}-06$ & $1.07 \mathrm{e}-06$ & $1.58 \mathrm{e}-06$ & $3.34 \mathrm{e}-06$ & $1.04 \mathrm{e}-06$ & $1.10 \mathrm{e}-06$ \\
\hline $\operatorname{ar} 2 p$ & 0.00105 & 0.00103 & 0.00115 & 0.00140 & 0.00103 & 0.00104 \\
\hline
\end{tabular}

Fonte: Elaborado pelo autor.

Notas: - Estatística t entre parênteses. Hansen testa a exogeneidade dos instrumentos, sob a hipótese nula, de que os instrumentos são exógenos, esta estatística do teste segue a distribuição $\chi$, onde é igual ao número de restrições sobre-identificadas. instrumentos as os defasamentos de todas as variáveis explicativas utilizadas em cada modelo, sendo que os desfasamentos variaram de 2 a 5. 5. distribuídos como $\mathrm{N}(0,1)$ sobre a hipótese nula de haver correlação serial.sế Os erros padrão foram corrigidos segundo metodologia de Windmeijer (2005). $\mathrm{Y}_{\mathrm{t}-1}$ representa as variáveis dependentes defasadas. -As variáveis explicativas AposEleição, Urbano, PES15, PES65, $P I B, T \_A N A L F 15 M$ e GINI foram mantidas em todas as estimações, mas os resultados foram retirados pela questão do espaço- As estimações foram realizadas utilizando o software econométrico Stata ${ }^{\circledR} 13$ for Mac.

O IPTU, que incide sobre a propriedade de terrenos e edifícios urbanos, é um dos tributos que é escolhido para ser reduzido em anos eleitorais. Esse é um imposto direto e facilmente visualizado pelos cidadãos, pois todo início de ano o mesmo deve ser quitado. Sendo assim, alterações nessa componente da receita são muito visíveis. Contudo, nenhuma das características analisadas parece condicionar o comportamento dessa variável em anos eleitorais, conforme indicam os resultados expostos na tabela 8. 
Tabela 9: Receitas ISS

\begin{tabular}{|c|c|c|c|c|c|c|}
\hline VARIABLES & $\begin{array}{l}(1) \\
\text { FemininoE }\end{array}$ & $\begin{array}{l}\text { (2) } \\
\text { EsquerdaE }\end{array}$ & $\begin{array}{l}\text { (3) } \\
\text { IdadeE }\end{array}$ & $\begin{array}{l}\text { (4) } \\
\text { SuperiorE }\end{array}$ & $\begin{array}{l}(5) \\
\text { PresE } \\
\end{array}$ & $\begin{array}{l}(6) \\
\text { GovE }\end{array}$ \\
\hline Eleição & $\begin{array}{l}-0.00152 \\
(-0.182)\end{array}$ & $\begin{array}{l}0.00109 \\
(0.121)\end{array}$ & $\begin{array}{l}0.0127 \\
(0.323)\end{array}$ & $\begin{array}{l}-0.00373 \\
(-0.340)\end{array}$ & $\begin{array}{l}0.00222 \\
(0.262)\end{array}$ & $\begin{array}{l}-0.00317 \\
(-0.358)\end{array}$ \\
\hline Esquerda & $\begin{array}{l}-0.000513 \\
(-0.0534)\end{array}$ & $\begin{array}{l}0.00467 \\
(0.434)\end{array}$ & $\begin{array}{l}-0.000488 \\
(-0.0507)\end{array}$ & $\begin{array}{l}-0.000458 \\
(-0.0476)\end{array}$ & $\begin{array}{l}0.00118 \\
(0.124)\end{array}$ & $\begin{array}{l}-0.000509 \\
(-0.0528)\end{array}$ \\
\hline Feminino & $\begin{array}{l}0.0222 \\
(1.396)\end{array}$ & $\begin{array}{l}0.0175 \\
(1.333)\end{array}$ & $\begin{array}{l}0.0176 \\
(1.335)\end{array}$ & $\begin{array}{l}0.0176 \\
(1.336)\end{array}$ & $\begin{array}{l}0.0173 \\
(1.331)\end{array}$ & $\begin{array}{l}0.0176 \\
(1.335)\end{array}$ \\
\hline Idade & $\begin{array}{l}0.000167 \\
(0.466)\end{array}$ & $\begin{array}{l}0.000166 \\
(0.462)\end{array}$ & $\begin{array}{l}0.000250 \\
(0.580)\end{array}$ & $\begin{array}{l}0.000171 \\
(0.476)\end{array}$ & $\begin{array}{l}0.000146 \\
(0.409)\end{array}$ & $\begin{array}{l}0.000170 \\
(0.473)\end{array}$ \\
\hline Superior & $\begin{array}{l}0.0174 * * \\
(2.537)\end{array}$ & $\begin{array}{l}0.0173 * * \\
(2.532)\end{array}$ & $\begin{array}{l}0.0174 * * \\
(2.541)\end{array}$ & $\begin{array}{l}0.0167 * * \\
(2.071)\end{array}$ & $\begin{array}{l}0.0170 * * \\
(2.504)\end{array}$ & $\begin{array}{l}0.0174 * * \\
(2.544)\end{array}$ \\
\hline Pres & $\begin{array}{l}0.0250 * \\
(1.870)\end{array}$ & $\begin{array}{l}0.0254 * \\
(1.899)\end{array}$ & $\begin{array}{l}0.0250 * \\
(1.868)\end{array}$ & $\begin{array}{l}0.0250 * \\
(1.867)\end{array}$ & $\begin{array}{l}0.0381 * * \\
(2.513)\end{array}$ & $\begin{array}{l}0.0250^{*} \\
(1.870)\end{array}$ \\
\hline Gov & $\begin{array}{l}0.0216^{* * * *} \\
(2.870)\end{array}$ & $\begin{array}{l}0.0218 \text { **** } \\
(2.889)\end{array}$ & $\begin{array}{l}0.0216^{* * * *} \\
(2.867)\end{array}$ & $\begin{array}{l}0.0217 \text { *** } \\
(2.870)\end{array}$ & $\begin{array}{l}0.0218 \text { **** } \\
(2.909)\end{array}$ & $\begin{array}{l}0.0208^{* *} * \\
(2.210)\end{array}$ \\
\hline FemininoE & $\begin{array}{l}-0.0172 \\
(-0.586)\end{array}$ & & & & & \\
\hline EsquerdaE & & $\begin{array}{l}-0.0198 \\
(-1.141)\end{array}$ & & & & \\
\hline IdadeE & & & $\begin{array}{l}-0.000294 \\
(-0.406)\end{array}$ & & & \\
\hline SuperiorE & & & & $\begin{array}{l}0.00264 \\
(0.193)\end{array}$ & & \\
\hline PresE & & & & & $\begin{array}{l}-0.0610 * * * \\
(-2.618)\end{array}$ & \\
\hline GovE & & & & & & $\begin{array}{l}0.00310 \\
(0.176)\end{array}$ \\
\hline Observations & 24,508 & 24,508 & 24,508 & 24,508 & 24,508 & 24,508 \\
\hline Number of Codigo & 2,228 & 2,228 & 2,228 & 2,228 & 2,228 & 2,228 \\
\hline Teste Wald & 0.6209 & 0.3538 & 0.7453 & 0.7773 & 0.0174 & 0.7800 \\
\hline hansenp & 0.259 & 0.260 & 0.255 & 0.252 & 0.277 & 0.254 \\
\hline $\operatorname{ar} 1 p$ & 0 & 0 & 0 & 0 & 0 & 0 \\
\hline $\operatorname{ar} 2 \mathrm{p}$ & 0.146 & 0.149 & 0.147 & 0.147 & 0.149 & 0.147 \\
\hline
\end{tabular}

Fonte: Elaborado pelo autor.

Notas: - Estatística t entre parênteses. Hansen testa a exogeneidade dos instrumentos, sob a hipótese nula, de que os instrumentos são exógenos, esta estatística do teste segue a distribuição $\chi$, onde é igual ao número de restrições sobre-identificadas. instrumentos as os defasamentos de todas as variáveis explicativas utilizadas em cada modelo, sendo que os desfasamentos variaram de 2 a 5. . distribuídos como $\mathrm{N}(0,1)$ sobre a hipótese nula de haver correlação serial.sế Os erros padrão foram corrigidos segundo metodologia de Windmeijer (2005). $\mathrm{Y}_{\mathrm{t}-1}$ representa as variáveis dependentes defasadas. -As variáveis explicativas AposEleição, Urbano, PES15, PES65, $P I B, T \_A N A L F 15 M$ e GINI foram mantidas em todas as estimações, mas os resultados foram retirados pela questão do espaço- As estimações foram realizadas utilizando o software econométrico Stata ${ }^{\circledR} 13$ for Mac.

O ISS, que incide sobre serviços prestados no município, é um imposto indireto que somente os prestadores de serviços é que observam alterações no seu comportamento. Dado isso, notase nos resultados expostos na tabela 9, que os municípios administrados por prefeitos do mesmo partido do presidente da República, apresentam quedas de 5,88\% nesse tributos em anos eleitoral, o que, segundo Rogoff e Sibert (1988) indicam um comportamento oportunista. 
Tabela 10: Receitas ITBI

\begin{tabular}{|c|c|c|c|c|c|c|}
\hline VARIABLES & $\begin{array}{l}(1) \\
\text { FemininoE }\end{array}$ & $\begin{array}{l}\text { (2) } \\
\text { EsquerdaE }\end{array}$ & $\begin{array}{l}(3) \\
\text { IdadeE }\end{array}$ & $\begin{array}{l}\text { (4) } \\
\text { SuperiorE }\end{array}$ & $\begin{array}{l}(5) \\
\text { PresE }\end{array}$ & $\begin{array}{l}\text { (6) } \\
\text { GovE }\end{array}$ \\
\hline Eleição & $\begin{array}{l}-0.0678 * * * \\
(-4.383)\end{array}$ & $\begin{array}{l}-0.0718 * * * \\
(-4.715)\end{array}$ & $\begin{array}{l}-0.0357 \\
(-0.735)\end{array}$ & $\begin{array}{l}-0.0848 * * * \\
(-4.921)\end{array}$ & $\begin{array}{l}-0.0686 * * * \\
(-4.467)\end{array}$ & $\begin{array}{l}-0.0699 * * * \\
(-4.148)\end{array}$ \\
\hline Esquerda & $\begin{array}{l}0.0121 \\
(0.736)\end{array}$ & $\begin{array}{l}0.00728 \\
(0.420)\end{array}$ & $\begin{array}{l}0.0121 \\
(0.736)\end{array}$ & $\begin{array}{l}0.0123 \\
(0.740)\end{array}$ & $\begin{array}{l}0.0121 \\
(0.736)\end{array}$ & $\begin{array}{l}0.0121 \\
(0.733)\end{array}$ \\
\hline Feminino & $\begin{array}{l}0.0194 \\
(0.680)\end{array}$ & $\begin{array}{l}0.0160 \\
(0.593)\end{array}$ & $\begin{array}{l}0.0158 \\
(0.590)\end{array}$ & $\begin{array}{l}0.0164 \\
(0.600)\end{array}$ & $\begin{array}{l}0.0159 \\
(0.591)\end{array}$ & $\begin{array}{l}0.0159 \\
(0.590)\end{array}$ \\
\hline Idade & $\begin{array}{l}-0.00107 \\
(-1.576)\end{array}$ & $\begin{array}{l}-0.00108 \\
(-1.577)\end{array}$ & $\begin{array}{l}-0.000894 \\
(-1.280)\end{array}$ & $\begin{array}{l}-0.00108 \\
(-1.576)\end{array}$ & $\begin{array}{l}-0.00107 \\
(-1.576)\end{array}$ & $\begin{array}{l}-0.00107 \\
(-1.575)\end{array}$ \\
\hline Superior & $\begin{array}{l}-0.0217 \\
(-1.643)\end{array}$ & $\begin{array}{l}-0.0218 \\
(-1.643)\end{array}$ & $\begin{array}{l}-0.0216 \\
(-1.641)\end{array}$ & $\begin{array}{l}-0.0320 * * \\
(-2.265)\end{array}$ & $\begin{array}{l}-0.0217 \\
(-1.641)\end{array}$ & $\begin{array}{l}-0.0216 \\
(-1.641)\end{array}$ \\
\hline Pres & $\begin{array}{l}-0.0102 \\
(-0.534)\end{array}$ & $\begin{array}{l}-0.0107 \\
(-0.556)\end{array}$ & $\begin{array}{l}-0.0102 \\
(-0.533)\end{array}$ & $\begin{array}{l}-0.0106 \\
(-0.548)\end{array}$ & $\begin{array}{l}-0.00999 \\
(-0.474)\end{array}$ & $\begin{array}{l}-0.0102 \\
(-0.533)\end{array}$ \\
\hline Gov & $\begin{array}{l}-0.00804 \\
(-0.670)\end{array}$ & $\begin{array}{l}-0.00818 \\
(-0.679)\end{array}$ & $\begin{array}{l}-0.00807 \\
(-0.674)\end{array}$ & $\begin{array}{l}-0.00807 \\
(-0.666)\end{array}$ & $\begin{array}{l}-0.00802 \\
(-0.667)\end{array}$ & $\begin{array}{l}-0.00951 \\
(-0.696)\end{array}$ \\
\hline FemininoE & $\begin{array}{l}-0.0131 \\
(-0.404)\end{array}$ & & & & & \\
\hline EsquerdaE & & $\begin{array}{l}0.0186 \\
(0.826)\end{array}$ & & & & \\
\hline IdadeE & & & $\begin{array}{l}-0.000639 \\
(-0.727)\end{array}$ & & & \\
\hline SuperiorE & & & & $\begin{array}{l}0.0362 * * \\
(2.220)\end{array}$ & & \\
\hline PresE & & & & & $\begin{array}{l}-0.00118 \\
(-0.0357)\end{array}$ & \\
\hline GovE & & & & & & $\begin{array}{l}0.00569 \\
(0.243)\end{array}$ \\
\hline Observations & 24,508 & 24,508 & 24,508 & 24,508 & 24,508 & 24,508 \\
\hline Number of Codigo & 2,228 & 2,228 & 2,228 & 2,228 & 2,228 & 2,228 \\
\hline Teste Wald & 0.1462 & 0.0014 & 0.4777 & 0.0000 & 0.0735 & 0.0276 \\
\hline hansenp & 0.157 & 0.155 & 0.158 & 0.153 & 0.156 & 0.156 \\
\hline $\operatorname{ar} 1 \mathrm{p}$ & 0 & 0 & 0 & 0 & 0 & 0 \\
\hline $\operatorname{ar} 2 \mathrm{p}$ & 0.000946 & 0.00103 & 0.000932 & 0.00112 & 0.000978 & 0.000959 \\
\hline
\end{tabular}

Fonte: Elaborado pelo autor.

Notas: - Estatística t entre parênteses. Hansen testa a exogeneidade dos instrumentos, sob a hipótese nula, de que os instrumentos são exógenos, esta estatística do teste segue a distribuição $\chi$, onde é igual ao número de restrições sobre-identificadas. instrumentos as os defasamentos de todas as variáveis explicativas utilizadas em cada modelo, sendo que os desfasamentos variaram de 2 a

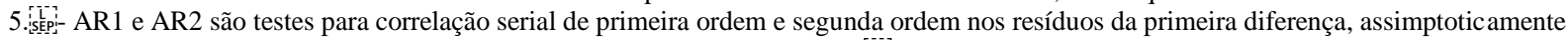
distribuídos como $\mathrm{N}(0,1)$ sobre a hipótese nula de haver correlação serial.jș Windmeijer (2005). $\mathrm{Y}_{\mathrm{t}-1}$ representa as variáveis dependentes defasadas. -As variáveis explicativas AposEleição, Urbano, PES15, PES65, $P I B, T \_A N A L F 15 M$ e GINI foram mantidas em todas as estimações, mas os resultados foram retirados pela questão do espaço- As estimações foram realizadas utilizando o software econométrico Stata ${ }^{\circledR} 13$ for Mac.

O ITBI, que é conhecido como o imposto inter vivos e que incide sobre as transferências da propriedades de prédios urbanos, excluindo os de sucessão, da mesma forma que o IPTU, ele é facilmente percebido, mas somente quando uma transferência é realizada. Quando se analisa o impacto das características dos prefeitos sobre esse imposto (Tabela 10), percebe-se que os prefeitos com ensino superior completo, reduzem menos o mesmo em anos eleitorais, quando comparado aos demais $(-4,86 \%)$, o que indica que o nível de educação do prefeito, tem um impacto redutor da magnitude do CPO no ITBI, pois as reduções nesse imposto é menor nos anos eleitorais, sendo que segundo Rogoff e Sibert (1988) o comportamento oportunista típico pelo lado dos impostos é a redução dos mesmos em anos com votação, ou seja, se eles diminuem menos o ITBI, estão a ser "menos oportunistas". 
Tabela 11: Receitas Taxas e Tarifas

\begin{tabular}{|c|c|c|c|c|c|c|}
\hline VARIABLES & $\begin{array}{l}(1) \\
\text { FemininoE }\end{array}$ & $\begin{array}{l}\text { (2) } \\
\text { EsquerdaE }\end{array}$ & $\begin{array}{l}\text { (3) } \\
\text { IdadeE }\end{array}$ & $\begin{array}{l}(4) \\
\text { SuperiorE }\end{array}$ & $\begin{array}{l}\text { (5) } \\
\text { PresE }\end{array}$ & $\begin{array}{l}\text { (6) } \\
\text { GovE }\end{array}$ \\
\hline Eleição & $\begin{array}{l}-0.150 * * * \\
(-17.36)\end{array}$ & $\begin{array}{l}-0.161 * * * \\
(-16.90)\end{array}$ & $\begin{array}{l}-0.187 * * * \\
(-3.999)\end{array}$ & $\begin{array}{l}-0.168 * * * \\
(-14.06)\end{array}$ & $\begin{array}{l}-0.152 * * * \\
(-17.07)\end{array}$ & $\begin{array}{l}-0.145 * * * \\
(-15.13)\end{array}$ \\
\hline Esquerda & $\begin{array}{l}0.00505 \\
(0.226)\end{array}$ & $\begin{array}{l}-0.0120 \\
(-0.530)\end{array}$ & $\begin{array}{l}0.00505 \\
(0.226)\end{array}$ & $\begin{array}{l}0.00510 \\
(0.228)\end{array}$ & $\begin{array}{l}0.00397 \\
(0.177)\end{array}$ & $\begin{array}{l}0.00517 \\
(0.231)\end{array}$ \\
\hline Feminino & $\begin{array}{l}0.0114 \\
(0.332)\end{array}$ & $\begin{array}{l}0.0147 \\
(0.458)\end{array}$ & $\begin{array}{l}0.0148 \\
(0.460)\end{array}$ & $\begin{array}{l}0.0147 \\
(0.460)\end{array}$ & $\begin{array}{l}0.0146 \\
(0.456)\end{array}$ & $\begin{array}{l}0.0147 \\
(0.459)\end{array}$ \\
\hline Idade & $\begin{array}{l}0.00143 \\
(1.504)\end{array}$ & $\begin{array}{l}0.00143 \\
(1.505)\end{array}$ & $\begin{array}{l}0.00123 \\
(1.269)\end{array}$ & $\begin{array}{l}0.00144 \\
(1.512)\end{array}$ & $\begin{array}{l}0.00144 \\
(1.509)\end{array}$ & $\begin{array}{l}0.00143 \\
(1.502)\end{array}$ \\
\hline Superior & $\begin{array}{l}0.0393 * * \\
(2.297)\end{array}$ & $\begin{array}{l}0.0394 * * \\
(2.300)\end{array}$ & $\begin{array}{l}0.0393 * * \\
(2.295)\end{array}$ & $\begin{array}{l}0.0282 \\
(1.594)\end{array}$ & $\begin{array}{l}0.0393 * * \\
(2.293)\end{array}$ & $\begin{array}{l}0.0393 * * \\
(2.293)\end{array}$ \\
\hline Pres & $\begin{array}{c}-0.000113 \\
(-0.00441)\end{array}$ & $\begin{array}{l}-0.00146 \\
(-0.0568)\end{array}$ & $\begin{array}{l}-8.57 e-05 \\
(-0.00333)\end{array}$ & $\begin{array}{l}-0.000108 \\
(-0.00419)\end{array}$ & $\begin{array}{l}-0.00702 \\
(-0.271)\end{array}$ & $\begin{array}{l}-0.000203 \\
(-0.00790)\end{array}$ \\
\hline Gov & $\begin{array}{l}0.0234 \\
(1.438)\end{array}$ & $\begin{array}{l}0.0229 \\
(1.409)\end{array}$ & $\begin{array}{l}0.0234 \\
(1.440)\end{array}$ & $\begin{array}{l}0.0234 \\
(1.438)\end{array}$ & $\begin{array}{l}0.0232 \\
(1.427)\end{array}$ & $\begin{array}{l}0.0277 * \\
(1.671)\end{array}$ \\
\hline FemininoE & $\begin{array}{l}0.0125 \\
(0.366)\end{array}$ & & & & & \\
\hline EsquerdaE & & $\begin{array}{l}0.0654 * * * \\
(3.936)\end{array}$ & & & & \\
\hline IdadeE & & & $\begin{array}{l}0.000740 \\
(0.843)\end{array}$ & & & \\
\hline SuperiorE & & & & $\begin{array}{l}0.0404 * * * \\
(2.656)\end{array}$ & & \\
\hline PresE & & & & & $\begin{array}{l}0.0328 \\
(1.539)\end{array}$ & \\
\hline GovE & & & & & & $\begin{array}{l}-0.0165 \\
(-0.859)\end{array}$ \\
\hline Observations & 24,508 & 24,508 & 24,508 & 24,508 & 24,508 & 24,508 \\
\hline Number of Codigo & 2,228 & 2,228 & 2,228 & 2,228 & 2,228 & 2,228 \\
\hline Teste Wald & 0.0000 & 0.0000 & 0.0001 & 0.0000 & 0.0000 & 0.0000 \\
\hline hansenp & 0.379 & 0.387 & 0.385 & 0.412 & 0.386 & 0.382 \\
\hline $\operatorname{ar} 1 \mathrm{p}$ & 0 & 0 & 0 & 0 & 0 & 0 \\
\hline $\operatorname{ar} 2 \mathrm{p}$ & 0.000962 & 0.000995 & 0.000990 & 0.00109 & 0.000951 & 0.000956 \\
\hline
\end{tabular}

Fonte: Elaborado pelo autor.

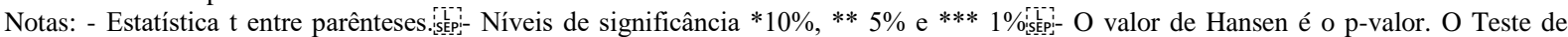
Hansen testa a exogeneidade dos instrumentos, sob a hipótese nula, de que os instrumentos são exógenos, esta estatística do teste segue a distribuição $\chi$, onde é igual ao número de restrições sobre-identificadas. instrumentos as os defasamentos de todas as variáveis explicativas utilizadas em cada modelo, sendo que os desfasamentos variaram de 2 a

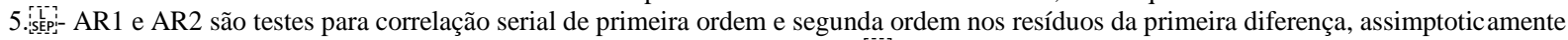
distribuídos como $\mathrm{N}(0,1)$ sobre a hipótese nula de haver correlação serial.jș Windmeijer (2005). $\mathrm{Y}_{\mathrm{t}-1}$ representa as variáveis dependentes defasadas. -As variáveis explicativas AposEleição, Urbano, PES15, PES65, $P I B, T \_A N A L F 15 M$ e GINI foram mantidas em todas as estimações, mas os resultados foram retirados pela questão do espaço- As estimações foram realizadas utilizando o software econométrico Stata ${ }^{\circledR} 13$ for Mac.

Por fim, ao analisar se as taxas e tarifas municipais, contatou-se, conforme incidam os resultados contidos na tabela 11 , que as receitais oriundas das taxas e tarifas são condicionadas pela ideologia do governante e pela formação superior. Os municípios cujo prefeito é de um partido de esquerda, apresentam, em anos eleitorais, menores reduções nas taxas e tarifas públicas $(-9,56 \%)$ quando comparados aos de outras ideologias, enquanto os prefeitos com formação superior apresentam, tudo o resto igual, uma queda de $12,76 \%$ em anos com votações. Esse comportamento indica que a ideologia e o nível educacional do prefeito tem impacto redutor da magnitude do CPO nesse tributo. 


\section{CONCLUSÕES}

A existência de um comportamento oportunista nos moldes descritos por Rogoff e Sibert (1988) foi confirmada nas receitas tributárias dos municípios brasileiros. As recursos advindos de tributos são reduzidos em anos eleitorais e no posterior. As receitas advindas de operações de crédito e alienação de bens não são alteradas nos anos eleitorais. Quando são analisados os tributos em anos eleitorais, constatou-se que os prefeitos brasileiros escolhem reduzir os dois impostos diretos que possuem sobre a sua competência (ITBI e IPTU) e mantêm o ISS inalterado. As Tarifas e taxas, que possuem caraterísticas similares aos impostos diretos, dada a sua facilidade de percepção pelos cidadãos, também são reduzidas em anos com eleições.

Sobre o impacto das características dos prefeitos sobre o oportunismo pré-eleitoral, os resultados indicam que a idade, o nível educacional, a ideologia e o alinhamento ao presidente da República e ao governador de estado, possuem impacto condicionante dos ciclos políticoorçamentários ao nível da receita. O gênero não parece ter impacto no oportunismo. Para trabalhos futuros é importante expandir a analise do impacto das características dos prefeitos sobre as despesas públicas, tanto segundo a classificação econômica, como por funções.

\section{REFERERÊNCIAS}

ANDRIKOPOULOS, A.; LOIZIDES, I.; PRODROMIDIS, K. (2006) Taxation and political business cycles in EU economies. Apllied Economics, n.38, p. 1761-1774, 2006.

ALESINA, A.; PARADISI, M. Political budget cycles: evidence from Italian cities. NBER Working Paper, n. 20570, 2014.

ARELLANO, M.; BOND, S. Some tests of specification for panel data: Monte Carlo evidence and an application to employment equations. The Review of Economic Studies, n. 58, p. 277-297, 1991.

; BOVER, O. Another look at the instrumental variable estimation of errorcomponent models. Journal of Econometrics, n. 68, p. 29-51, 1995.

ASHWORTH, J.; HEYNDELS, B. Tax structure turbulance in OECD coutries. Public Choice. n. 111, p. 347-376, 2002.

BINET, M. E., PENTECÔTE, J. S. Tax degression and the political budget cycle in French municipalities. Applied Economics Letters v.11, n. 14, p. 905-908, 2004.

BRASIL. Constituição, 1988.

Lei Complementar $\mathrm{n}^{\circ} 101$, de 04 de maio de 2000.

BLUNDELL, R., BOND, S. Initial conditions and moment restrictions in dynamic panel data 
models. Journal of Econometrics, n. 87, p. 115-143, 1998.

EHRHART, H. Elections and the structure of taxation in developing countries. Public Choice, n. 156, p. 195-211, 2013.

FOREMNY, D.; FREIER, R.; MOESSINGER, M. D.; YETER, M. (Overlapping political budget cycles in the legislative and the executive. Centre for European Economic Research Discussion Paper 14-099, 2014.

HANSEN, L. P. Large sample properties of generalized method of moment's estimator. Econometrica, v. 50, n. 4, 1029-1054, 1982.

KARAKAŞ, M. Political business cycles in Turkey: a fiscal approach. Journal of Management \& Economics, v. 20, n. 1, p. 245-262, 2013.

KATSIMI, M.; SARANTIDES, V. Do elections affect the composition of fiscal policy in developed, estabilished democracies? Public Choice, n. 151, p. 325-362, 2012.

KLIEN, M. Tariff increases over electoral cycle: a question of size and salience. European Journal of Political Economy, n. 36, p. 228-242, 2014.

MENDES, M. Federalismo Fiscal e crescimento do governo: evidências eleitorais para o Brasil. In: ANPEC - XXXII Encontro Nacional de Economia, 2004.

MENEGUIN, F. B.; BUGARIN, M. S.; CARVALHO, A. X. O que leva um governante à reeleição. Texto para discussão IPEA,n. 1135, 2005.

MIKESSELL, J. L. Election periods and state tax policy cycles. Public Choice, v. 33 n. 3, 99-106, 1978.

MOROZUMI, A.; VEIGA, F. J.; VEIGA, L. G. Conditional electoral effects on the composition of public expenditures and revenue: evidence from a large panel of countries. NIPE-WP 23/2014, 2014.

NAKAGUMA, M. Y.; BENDER, S. A Emenda da Reeleição e a Lei de Responsabilidade Fiscal: impactos sobre ciclos políticos e performance fiscal dos estados (1986-2002). Economia Aplicada, v. 10, n. 3, p. 377-397, 2006.

REYNOLDS, C. L. (2014). State politics, tuition, and the dynamics of a political budget cycle. Empirical Economics. n. 46, p.1241-1270, 2014.

REZENDE, F. Federalismo fiscal no Brasil. Revista de Economia Política, v. 15, n.3, 5-17, 1995.

; SIBERT, A. Elections and macroeconomic policy cycles. Review of Economics Studies, n. 55, p. 1-16, 1988.

ROODMAN, D. How to Do xtabond2: An Introduction to Difference and "System GMM in Stata. Stata Journal, v.9, n. 1, p. 86-136, 2009.

SAKURAI, S. N.; MENEZES-FILHO, N. Opportunistic and partisan election cycles in Brazil: new evidence at the municipal level. Public Choice, n. 148, p. 233-247, 2011.

SERRA, J.; AFONSO, J. R. R. O federalismo fiscal à brasileira: algumas reflexões. Revista do BNDES, v. 12, n. 6, p. 3-30, 1999.

VERBEEK, M. A Guide to Modern Econometrics, John Wiley \& Sons, Ltd.: Chichester, 2009. 
VICENTE, C.; BENITO, B.; BASTIDA, F. Transparency and political budget cycles at municipal level. Swiss Political Science Review, v.19, n. 2, p. 139-156, 2013.

VOLKERINK, B.; DE HAAN, J. Political and institutional determinants of the tax mix: an empirical investigation for OECD countries. SOM Research Report 99E05, University of Groningen, p. 1-43, 1999.

WINDMEIJER, F. (2000). A finite sample correction for the variance of linear two-step GMM estimators. Institute of Fiscal Studies Working Paper Series No W00/19, 2000.

YOO, K. R. Intervention analysis of electoral tax cycle: the case of Japan. Public Choice, n. 96, p. 241-258, 1998. 